\title{
LuxAB-Based Microbial Cell Factories for the Sensing, Manufacturing and Transformation of Industrial Aldehydes
}

\author{
Thomas Bayer ${ }^{1,2}{ }^{*} \mathbb{D}$, Aileen Becker ${ }^{1}$, Henrik Terholsen ${ }^{1}{ }^{\mathbb{D}}$, In Jung Kim ${ }^{1}$, Ina Menyes ${ }^{1}$, Saskia Buchwald ${ }^{1}$, \\ Kathleen Balke ${ }^{1}$, Suvi Santala ${ }^{3}$, Steven C. Almo ${ }^{2}$ and Uwe T. Bornscheuer ${ }^{1, *(D)}$ \\ 1 Department of Biotechnology \& Enzyme Catalysis, Institute of Biochemistry, University of Greifswald, \\ Felix-Hausdorff-Straße 4, 17487 Greifswald, Germany; aileen.becker@uni-greifswald.de (A.B.); \\ henrik.terholsen@uni-greifswald.de (H.T.); in.kim@uni-greifswald.de (I.J.K.); \\ ina.menyes@uni-greifswald.de (I.M.); saskia.buchwald@online.de (S.B.); kathleen.balke@gmx.de (K.B.) \\ 2 Department of Biochemistry, Albert Einstein College of Medicine, 1300 Morris Park Avenue, \\ Bronx, NY 10461-1602, USA; steve.almo@einsteinmed.org \\ 3 Faculty of Engineering and Natural Sciences, Hervanta Campus, Tampere University, P.O. Box 527, \\ 33014 Tampere, Finland; suvi.santala@tuni.fi \\ * Correspondence: thomas.bayer@uni-greifswald.de (T.B.); uwe.bornscheuer@uni-greifswald.de (U.T.B.)
}

\section{check for}

updates

Citation: Bayer, T.; Becker, A.; Terholsen, H.; Kim, I.J.; Menyes, I.; Buchwald, S.; Balke, K.; Santala, S.; Almo, S.C.; Bornscheuer, U.T. LuxAB-Based Microbial Cell Factories for the Sensing, Manufacturing and Transformation of Industrial Aldehydes. Catalysts 2021, 11, 953. https://doi.org/10.3390/ catal11080953

Academic Editor: Omer Yehezkeli

Received: 15 July 2021

Accepted: 5 August 2021

Published: 10 August 2021

Publisher's Note: MDPI stays neutral with regard to jurisdictional claims in published maps and institutional affiliations.

Copyright: (c) 2021 by the authors. Licensee MDPI, Basel, Switzerland. This article is an open access article distributed under the terms and conditions of the Creative Commons Attribution (CC BY) license (https:// creativecommons.org/licenses/by/ $4.0 /)$
Abstract: The application of genetically encoded biosensors enables the detection of small molecules in living cells and has facilitated the characterization of enzymes, their directed evolution and the engineering of (natural) metabolic pathways. In this work, the LuxAB biosensor system from Photorhabdus luminescens was implemented in Escherichia coli to monitor the enzymatic production of aldehydes from primary alcohols and carboxylic acid substrates. A simple high-throughput assay utilized the bacterial luciferase-previously reported to only accept aliphatic long-chain aldehydes - to detect structurally diverse aldehydes, including aromatic and monoterpene aldehydes. LuxAB was used to screen the substrate scopes of three prokaryotic oxidoreductases: an alcohol dehydrogenase (Pseudomonas putida), a choline oxidase variant (Arthrobacter chlorophenolicus) and a carboxylic acid reductase (Mycobacterium marinum). Consequently, high-value aldehydes such as cinnamaldehyde, citral and citronellal could be produced in vivo in up to $80 \%$ yield. Furthermore, the dual role of $\mathrm{LuxAB}$ as sensor and monooxygenase, emitting bioluminescence through the oxidation of aldehydes to the corresponding carboxylates, promises implementation in artificial enzyme cascades for the synthesis of carboxylic acids. These findings advance the bio-based detection, preparation and transformation of industrially important aldehydes in living cells.

Keywords: biosensor; bioluminescence; luciferase; high-throughput screening; whole-cell biocatalysis; aldehyde production; enzyme cascade

\section{Introduction}

Great progress has been achieved in tailoring microorganisms for the biosynthesis of (non-)natural chemicals including but not restricted to: fatty acids and derivatives [1-3], aromatic and phenolic compounds [4-6] and secondary metabolites such as terpenoids $[7,8]$. In the context of the (bio-based) manufacturing of these compounds, aldehydes are of special interest not only as building blocks for pharmaceuticals but value-added products in the food, flavor and fragrance industries [9]. Enzymatically, aldehydes can be accessed through (1) decarboxylation reactions of 2-keto substrates [10] or fatty acids [11], (2) the readily established reductions of carboxylates by carboxylic acid reductases (CARs) [12-14] or (3) the oxidation of primary alcohols [9]. For the latter, only a few enzymes have been employed in living cells. One example is AlkJ, an alcohol dehydrogenase (ADH) from Pseudomonas putida (P. putida) being capable of oxidizing a variety of primary alcohols [15-17]. However, due to their high reactivity and cytotoxicity, aldehydes are rapidly metabolized by endogenous enzymes and do not accumulate in many microorganisms including (heterologous) hosts such as Escherichia coli (E. coli) $[9,18,19]$. To address this issue, the groups 
of Atsumi and Prather constructed E. coli platform strains by targeted gene knock-outs that reduced the reduction of aliphatic and aromatic aldehydes to the corresponding primary alcohols $[20,21]$. The latter strain was termed E. coli RARE, exhibiting reduced aromatic aldehyde-reducing activity [21].

The functional expression of heterologous enzymes and the overall performance of microbial cell factories - not only for the synthesis of aldehydes-are usually assessed by the qualitative and quantitative analysis of target metabolites through chromatographic methods. Time-consuming sample preparation and low to moderate sample throughput impede the characterization of new biocatalysts as well as the development and optimization of microbial factories [22-24]. These bottlenecks have been addressed by the implementation of genetically encoded biosensor systems featuring (allosteric) transcription factors (TFs), riboswitches or enzyme-coupled devices to detect small molecules [25-29]. To date, biosensors have guided the directed evolution of enzymes [30-32], the engineering of (natural) metabolic pathways by the high-throughput (HT) detection of metabolites [33-35], and the dynamic regulation of genetic circuits to improve pathway performance, as well as other applications [3,28,36-41]. To sense aromatic aldehydes (e.g., benzaldehyde, cinnamaldehyde and vanillin), TF-based systems have been used $[6,42,43]$. Since TFs usually exhibit narrow ligand binding profiles, the detection of structurally different molecules is limited $[4,42,44]$. As a complementary tool, the luciferase LuxAB from Photorhabdus luminescens (P. luminescens) was demonstrated to detect medium- and long-chain aliphatic aldehydes $\left(\mathrm{C}_{8}-\mathrm{C}_{14}\right)$ [45]. LuxAB was also used to monitor fatty aldehyde/wax ester production [2] and non-native alkane synthesis pathways [25] in Acinetobacter baylyi ADP1 (A. baylyi). As an alternative to biosensors, Ressmann et al. developed a HT assay to quantify different aldehydes in whole cells [46]: The heterologously produced aldehydes and exogenously added 2-amino-benzamidoximes (ABAOs) formed dihydroquinazolines, which could be detected spectrophotometrically [47]. While offering versatility, the assay depends on the multi-step synthesis of (substituted) ABAOs involving hazardous and toxic chemicals. Furthermore, the reaction with ABAOs irreversibly consumes target aldehydes.

In this work, the P. luminescens LuxAB biosensor, previously used in A. baylyi, was transferred to E. coli. This system provides a HT assay for aldehydes in vivo and was used to screen prokaryotic oxidoreductases for their aldehyde production capabilities. Since LuxAB is a monooxygenase (MO) that emits bioluminescence through the oxidation of aldehydes to the corresponding carboxylic acids (CAs) [45], it not only serves as a biosensor, but may also support the formation of industrially important carboxylates through an artificial enzymatic cascade starting from primary alcohols (Figure 1).

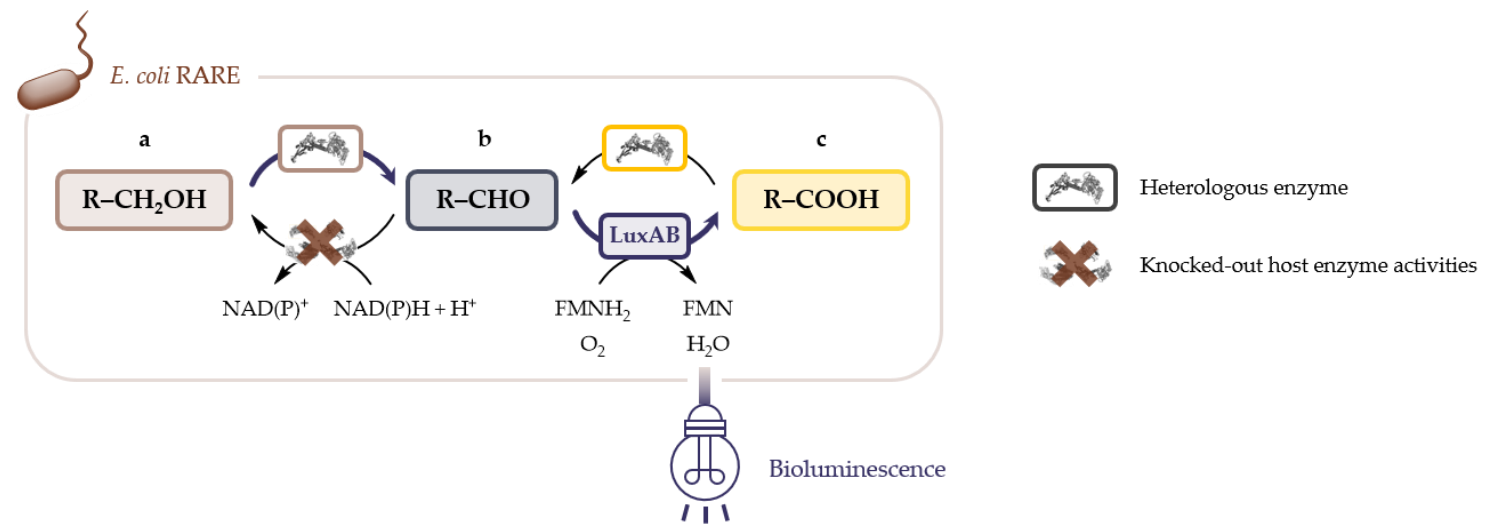

Figure 1. LuxAB-based microbial cell factory. Aldehydes (b) can be produced from primary alcohols (a) or CAs (c) by heterologously expressed enzymes (cofactors omitted for clarity) and serve as substrates for the MO LuxAB, yielding the corresponding CAs and detectable bioluminescence. The conversion of (aromatic) aldehydes into the corresponding alcohols is decreased in the E. coli RARE strain [21]. The combination of the oxidation step (a,b) and LuxAB (highlighted in blue) represents a new cascade producing CAs. 


\section{Results}

\subsection{LuxAB Biosensor Assembly and High-Troughput (HT) Detection of Aldehydes In Vivo}

Aldehydes are greatly desired chemicals—-for instance in the fragrance industry-and their bio-based production is highly demanded [9]. Hence, the fast characterization of new biocatalysts and easy detection of aldehydes are equally important. TF-based systems have been successfully employed to sense them but showed narrow ligand binding profiles [44]. This selectivity prompted us to implement the LuxAB system, described to sense a variety of aliphatic aldehydes [45], in the well-established biotechnology host E. coli.

For the construction of the biosensor device, the $\operatorname{lux} A B$ coding region was amplified from pAK400c/iluxAB_Cm ${ }^{r}$, which was previously constructed for the integration of luxAB into the $A$. baylyi genome and the monitoring of intracellular aldehyde levels $\left(\leq \mathrm{C}_{18}\right)[2,48]$. Subcloning of $l u x A B$ under the control of a constitutive T5 promoter into the target $\mathrm{pCDFDuet}-1$ vector was facilitated by a modified sequence and ligation-independent cloning (SLIC) procedure $[49,50]$, yielding pLuxAB (Table S10). Functionality of the biosensor system was tested in E. coli RARE resting cells (RCs) as described in this study. Supplementation of octanal (2b), nonanal (3b) and decanal $(\mathbf{4 b})$ increased the bioluminescence by, roughly, 13,000-, 14,000- and 37,000-fold, respectively, in RCs expressing LuxAB in 96-well plates after $3 \mathrm{~min}$ (Figure 2A). The fold increase in bioluminescence above background caused by the presence of aldehydes was calculated as described in the materials and methods (Section 4.4). These results are supported by the initial research characterizing the substrate range of $P$. luminescens LuxAB [45].

A

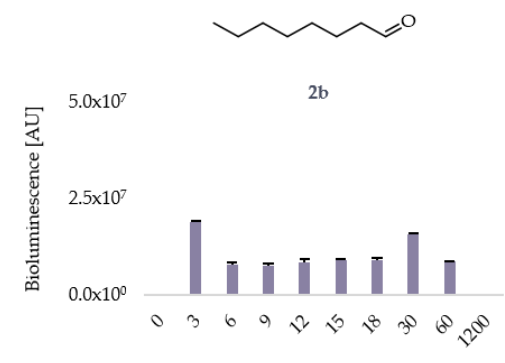

B
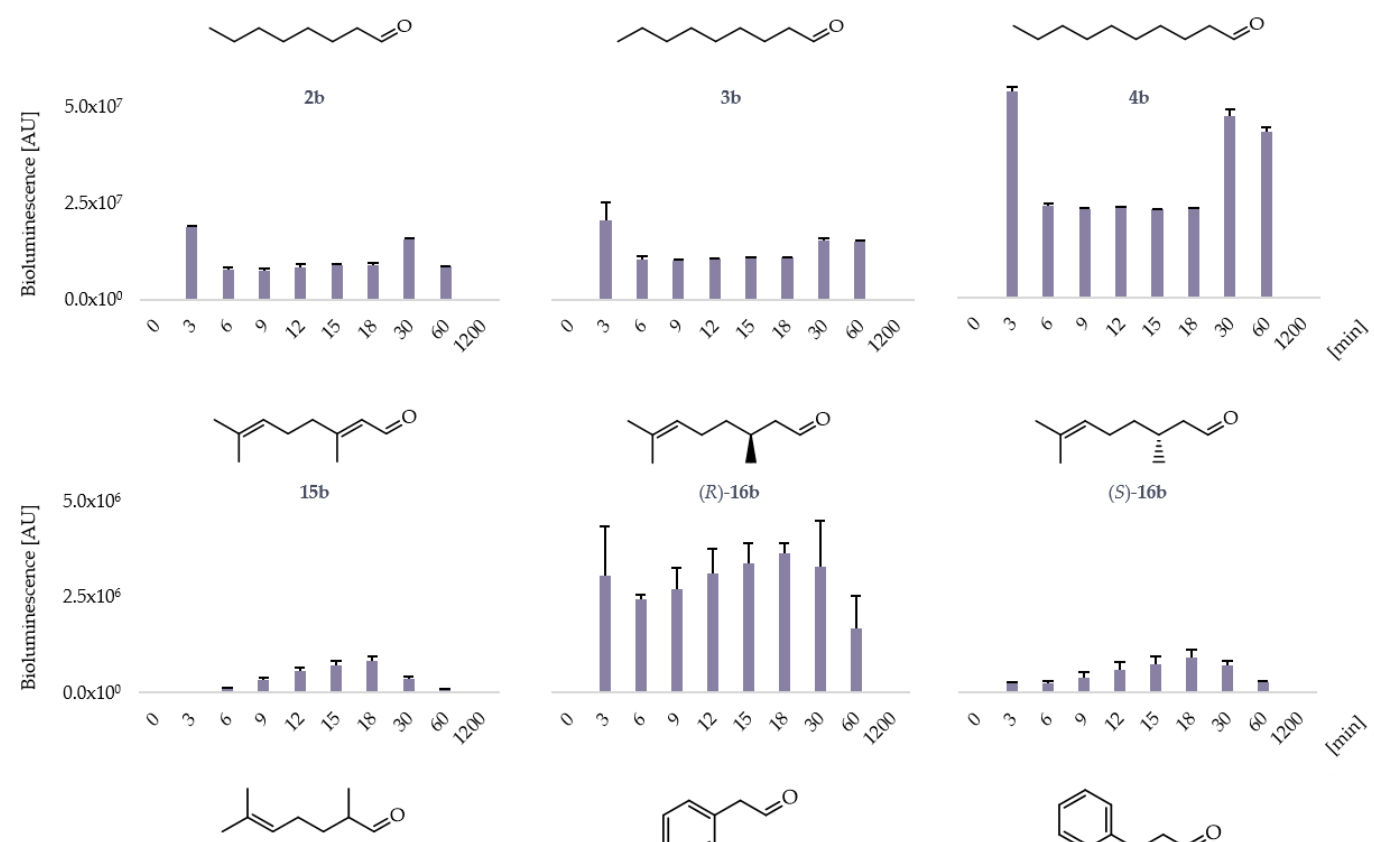

$17 \mathrm{~b}$
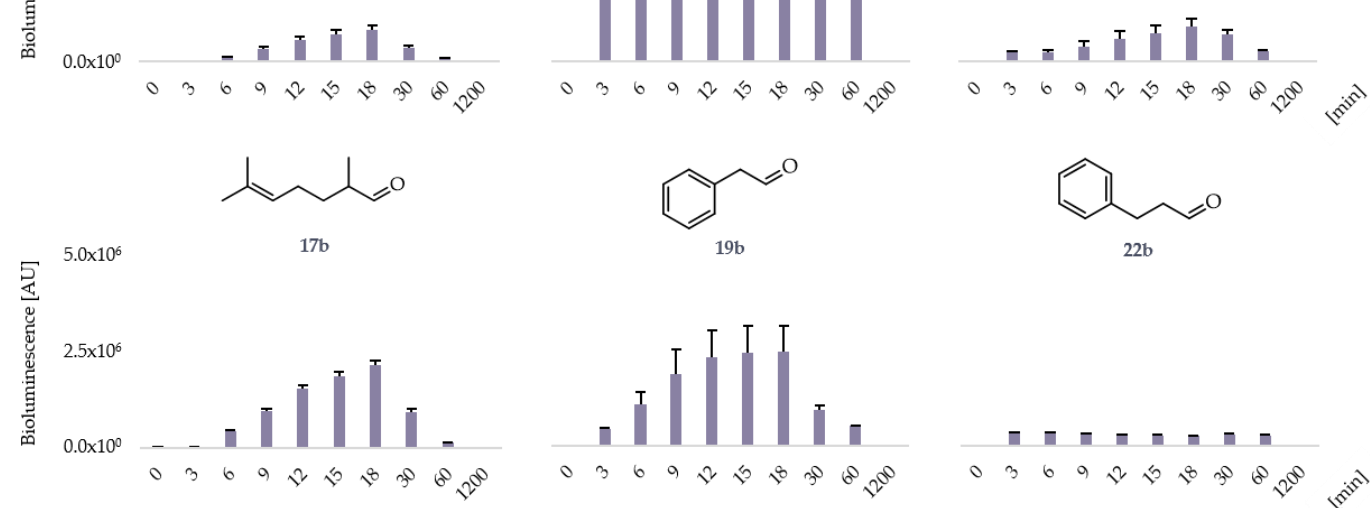

$22 \mathrm{~b}$

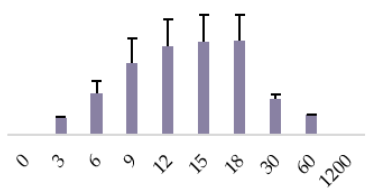

Figure 2. Aldehyde detection by the LuxAB biosensor in E. coli. (A) the bioluminescence greatly increased in the presence of previously reported aliphatic aldehydes (2-4b). (B) selected new substrates of LuxAB included monoterpene aldehydes $(\mathbf{1 5}-\mathbf{1 7 b})$ and aliphatic aldehydes with aromatic endgroups (19b and 22b). Experiments performed with RCs of E. coli RARE $\left(\mathrm{OD}_{600} \approx 10.0\right)$ expressing LuxAB from pLuxAB in the presence of $1 \mathrm{mM}$ aldehyde and $1 \%(v / v)$ ethanol as co-solvent; data presented as mean values + standard deviation (SD) of biological replicates $(n \geq 3)$. 
To further investigate the aldehyde detection scope of LuxAB beyond reported aldehyde classes, the bioluminescence was monitored in the presence of different monoterpene (15-17b) and aromatic (18-25b) aldehydes at $1 \mathrm{mM}$ (Figure 2B; selected examples) and $0.1 \mathrm{mM}$ final concentration (Figure S5). Interestingly, all tested terpene aldehydes increased the bioluminescence, including citral $(\mathbf{1 5 b}$; applied as a commercial mixture of the $E$ - and Z-isomers geranial and neral), citronellal (16b), with a clear preference for the $(R)$-enantiomer, and melonal (17b). (R)-16b and $\mathbf{1 7 b}$, for example, increased the bioluminescence almost 2500- and 1500-fold, respectively. Surprisingly, 2-phenyl ethanal (19b) and 3-phenyl propanal (22b) also yielded bioluminescence (1700- and 230-fold increase, respectively, after $18 \mathrm{~min}$; Figure 2B), whereas benzaldehyde (18b), cuminaldehyde (20b), trans-cinnamaldehyde (21b) and the tolualdehydes (23-25b) did not under these conditions (data not shown). The highest bioluminescence signals were detected at varying time points, which might indicate different rates and/or mechanisms of substrate uptake for aliphatic, monoterpene and aromatic aldehydes. Subsequently, the suitability of the LuxAB biosensor to detect aldehydes enzymatically produced in situ was determined. Therefore, three different prokaryotic oxidoreductases were selected: (1) the ADH AlkJ from P. putida, (2) a CAR from Mycobacterium marinum $\left(\mathrm{CAR}_{M m}\right)$ and (3) a choline oxidase variant from Arthrobacter chlorophenolicus (CO- $6_{A c}$ ), which has only been characterized in vitro [51]. AlkJ is known to oxidize aliphatic and aromatic primary alcohols [15-17], $\mathrm{CAR}_{M m}$ accepts both aliphatic and aromatic $C A s[52-54]$ and $C O-6_{A c}$ was initially engineered to oxidize hexanol (1a) [51].

The open reading frame (ORF) encoding alkJ was subcloned into a pACYC-derived backbone by SLIC, yielding pAYCQ/alkJ as described in the materials and methods section (Section 4.2) and the Supplementary Materials. Similarly, the gene encoding a phosphopantetheinyl transferase from Nocardia iowensis $\left(\mathrm{PPT}_{\mathrm{Ni}}\right.$ ) and the target pACYCDuet-1/ $\mathrm{car}_{\mathrm{Mm}}$ vector were assembled, yielding pACYCDuet-1/ $\mathrm{car}_{\mathrm{Mm}}: p p t_{\mathrm{Ni}}$. PPTs are required to posttranslationally modify apoCARs yielding catalytically active holoCAR enzymes $[52,53]$. For the expression of CO- $6_{A c}$ in E. coli, the gene was codon-optimized, synthesized and subcloned into pET28a by the BioCat $\mathrm{GmbH}$ (Heidelberg, Germany). All constructs were designed to have compatible origins of replication for the stable maintenance with pLuxAB in the same cell as well as complementary antibiotic markers for the selection of cotransformants [55] (Table S10). Competent E. coli RARE cells were co-transformed with pLuxAB and either of the oxidoreductase-coding plasmids. Successful expression of enzymes was verified by sodium dodecyl sulfate-polyacrylamide gel electrophoresis (SDSPAGE) analysis of whole-cell samples (Figure S4).

Finally, the HT conditions were employed to screen an extended substrate library containing the primary alcohols (1-7a, 18-25a), various diols (8-11a), simple monocarboxylates (1-7c, 18-25c), 6-hydroxy hexanoic acid (9c), 12-methyltridecanoic acid (12c), palmitoleic acid (13c), 12-hydroxy dodecanoic acid (14a) and dodecanedioic acid (14c).

All oxidoreductase-biosensor combinations yielded bioluminescence in the presence of substrates (Figure 3), suggesting the production of aldehydes in vivo. The HT screening indicated a broad substrate range for $\mathrm{AlkJ}$ and $\mathrm{CAR}_{M m}$ with an overlapping aldehyde production profile starting from primary alcohols and CAs, respectively. The highest bioluminescence could be observed with (unsubstituted) aliphatic substrates (1-7), also reflecting the preference of LuxAB to accept the corresponding aldehydes (Figure 2A). AlkJ and $C_{M m}$ have been shown to produce $4 \mathbf{b}$, for example, from decanol (4a) [56] and decanoic acid (4c) [54] and yielded 9281- and 989-fold increase in bioluminescence, respectively, after $1 \mathrm{~h}$ (Figure 3B). This almost 10-fold difference can be explained by the high bioluminescence background in RCs co-expressing LuxAB and $C_{A R} R_{M m}$ : Endogenous (free) fatty acids can be reduced by the heterologous CAR enzyme. The corresponding fatty aldehydes serve as substrates for LuxAB, hence, yielding bioluminescence. Noteworthy, in all RCs co-expressing LuxAB and one of the oxidoreductases, the bioluminescence slightly increased over time in the presence of $1 \%(v / v)$ organic co-solvent and the absence of substrate (Figure S7). Therefore, the experimental cut-off (XCO) value was introduced 
to assess the fold increase in bioluminescence above background actually caused by the enzymatic production of aldehydes from substrates. The XCO was determined as described under materials and methods (Section 4.4) and in the Supplementary Materials.

A

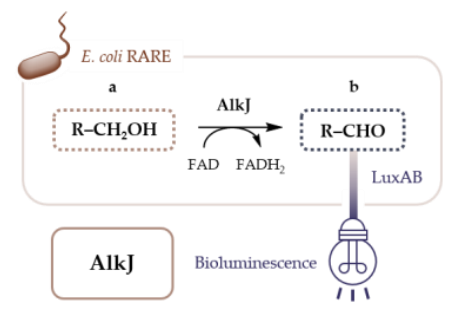

B

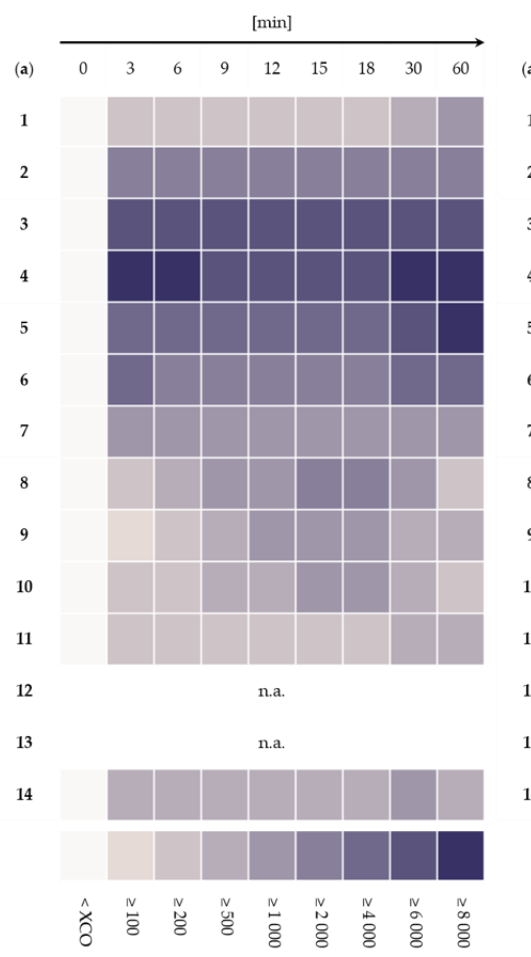

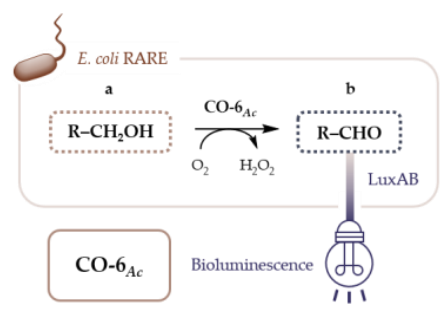
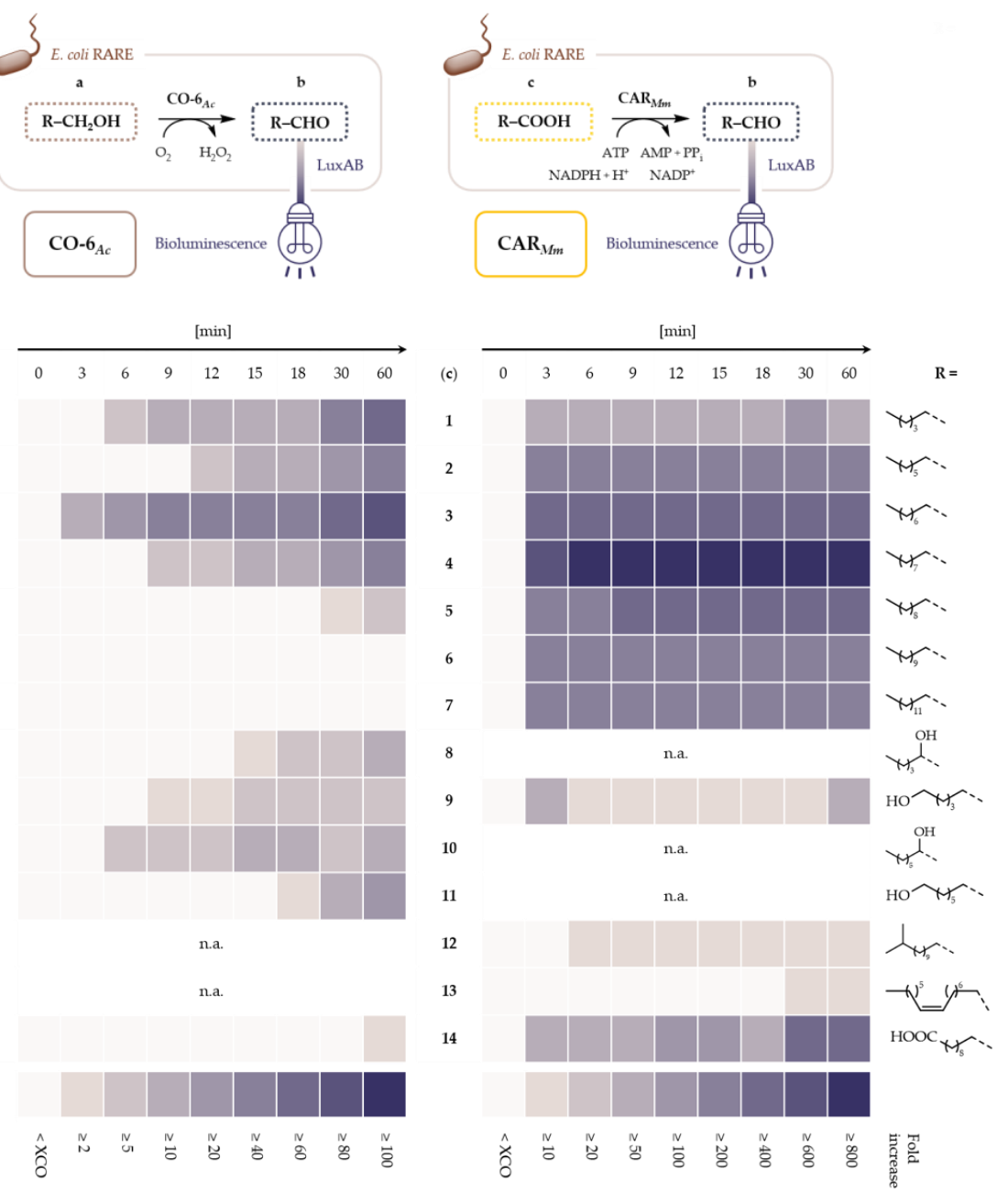

c

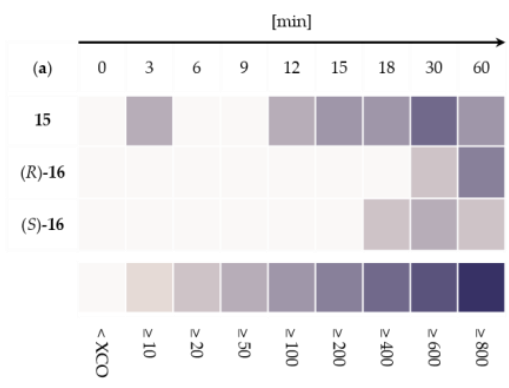

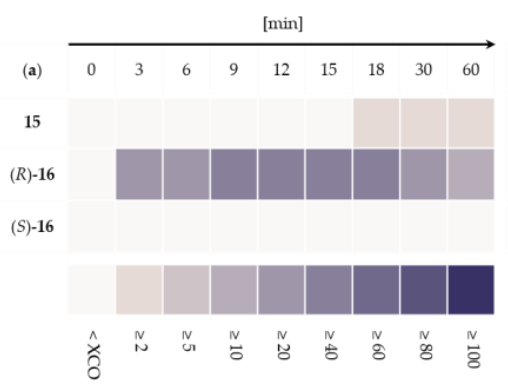

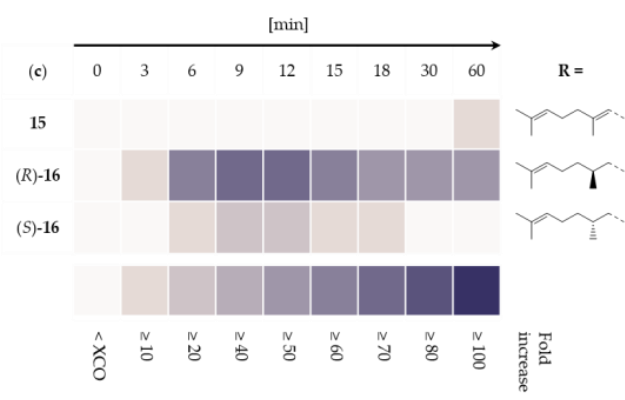

Figure 3. Cont. 


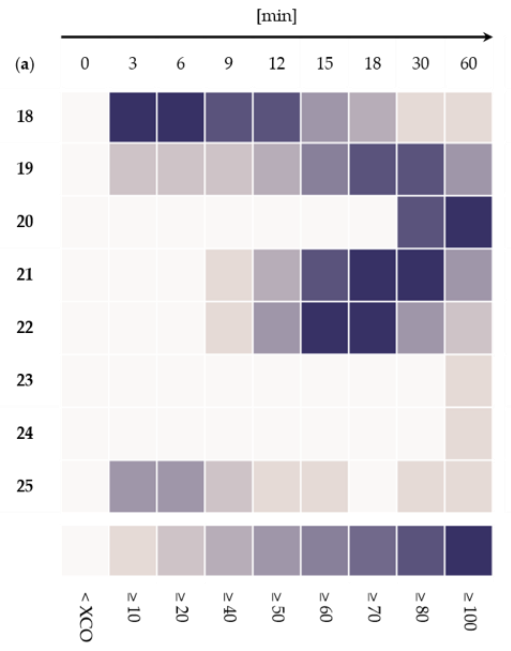

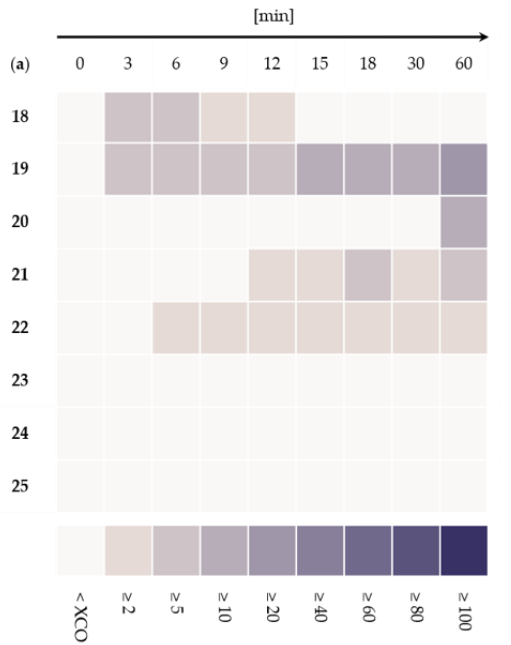

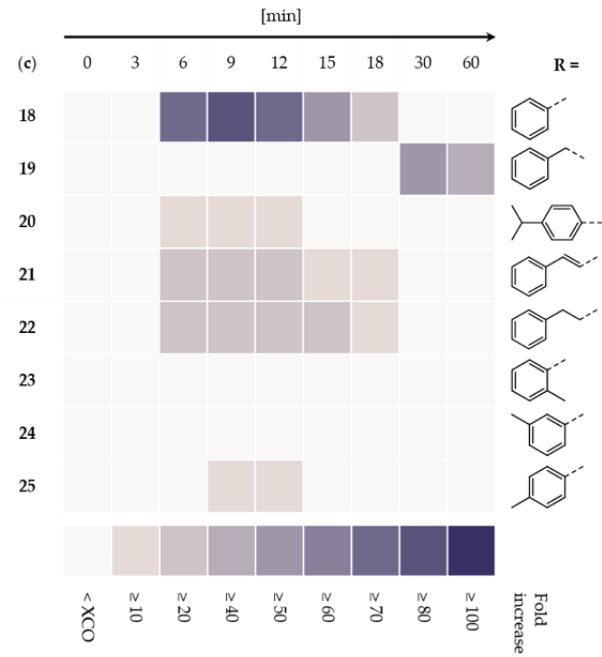

Figure 3. LuxAB-based HT screening of oxidoreductases in vivo. (A) bioluminescence suggests the production of aldehydes (b) from primary alcohols (a) by AlkJ (left) and CO-6 ${ }_{A c}$ (middle) or CAs (c) by CAR $\mathrm{Mm}_{m}$ (right; $\mathrm{PPT}_{N i}$ for posttranslational modification of $\mathrm{CAR}_{M m}$ omitted for clarity). The change in bioluminescence over time in response to the in situ production of aldehydes from (B) aliphatic substrates (1-14), (C) monoterpenes (15-16) and (D) aromatic compounds (18-25; continued on the next page). Shades of blue indicate the mean fold increase in bioluminescence based on biological replicates $(n \geq 3)$ above the XCO as defined in this study. Different scales reflect both varying background and the maximal bioluminescence. Experiments were performed in RCs of E. coli RARE $\left(\mathrm{OD}_{600} \approx 10.0\right)$ co-expressing LuxAB and the described oxidoreductase in the presence of $1 \mathrm{mM}$ substrate and $1 \%(v / v)$ ethanol as organic co-solvent; $n . a .=$ not available (12-13a, 8c, 10-11c). LuxAB-based HT screening of oxidoreductases in vivo (continued). Change in bioluminescence over time in response to the in situ production of aldehydes by AlkJ (left) and CO- $6_{A c}$ (middle) from primary aromatic alcohols (18-25a) or CAR (1m $_{2}$ (right) from aromatic CAs (18-25c).

The production of aldehydes from hexane-1,2-diol (8a), hexane-1,6-diol (9a), octane1,2-diol (10a) and octane-1,8-diol (11a) by AlkJ was suggested by the rise in bioluminescence (e.g., largest fold increase for 8a of almost 2500; Figure 3B). To the best of our knowledge, these substrates have not been reported to be converted by AlkJ. The oxidase CO- $6_{A c}$ had been shown to readily oxidize aliphatic 1-4a, the terminal diols $9 a$ and $11 a$, the terpenoid alcohols geraniol (15a) and citronellol (16a), as well as the aromatics benzyl alcohol (18a), 2-phenyl ethanol (19a) and cinnamyl alcohol (21a) in vitro [51]. The same substrate scope was observed under the HT assay conditions in vivo (Figure 3B-D). The low maximal bioluminescence in these reactions is probably caused by the competition for (dissolved) $\mathrm{O}_{2}$ by LuxAB and CO- 6 Ac and the cytotoxic $\mathrm{H}_{2} \mathrm{O}_{2}$ produced by the oxidase (Figure 3A) [57], decreasing cell viability and indirectly quenching bioluminescence. Additionally, the availability of flavins in E. coli might present another bottleneck [58], as discussed below. As mentioned above, the direct addition of aromatic aldehydes $\mathbf{1 8 b}$ and $\mathbf{2 1 b}$, for example, did not increase the bioluminescence in RCs solely expressing LuxAB. This behavior can be explained by the cytotoxicity of aldehydes at elevated concentrations [9]. Nonetheless, the formation of aldehydes in situ by AlkJ, CO- ${ }_{A c}$ and $\mathrm{CAR}_{M m}$ seemed compatible with the LuxAB biosensor system based on the detection of bioluminescence in samples presumably containing 18-22b (Figure 3D). Furthermore, the production of the value-added monoterpene aldehydes 15-16b was suggested (Figure 3C); 15-16b have not been reported as products of AlkJ- or CAR-catalyzed reactions. Consequently, biotransformations in whole cells expressing AlkJ or $\mathrm{CAR}_{\mathrm{Mm}} / \mathrm{PPT}_{\mathrm{Ni}}$ were performed to confirm the production of selected aldehydes, based on the results of the HT assay.

\subsection{Microbial Cell Factories for the Production and Transformation of Value-Added Aldehydes}

Biotransformations were carried out in RCs of E. coli RARE transformants. Focus was on unreported substrates including 4-isopropylbenzyl alcohol (20a), cinnamyl alcohol 
(21a), 2-methylbenzyl alcohol (23a) and 4-methylbenzyl alcohol (25a) for AlkJ (Figure 4)

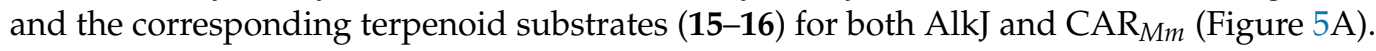

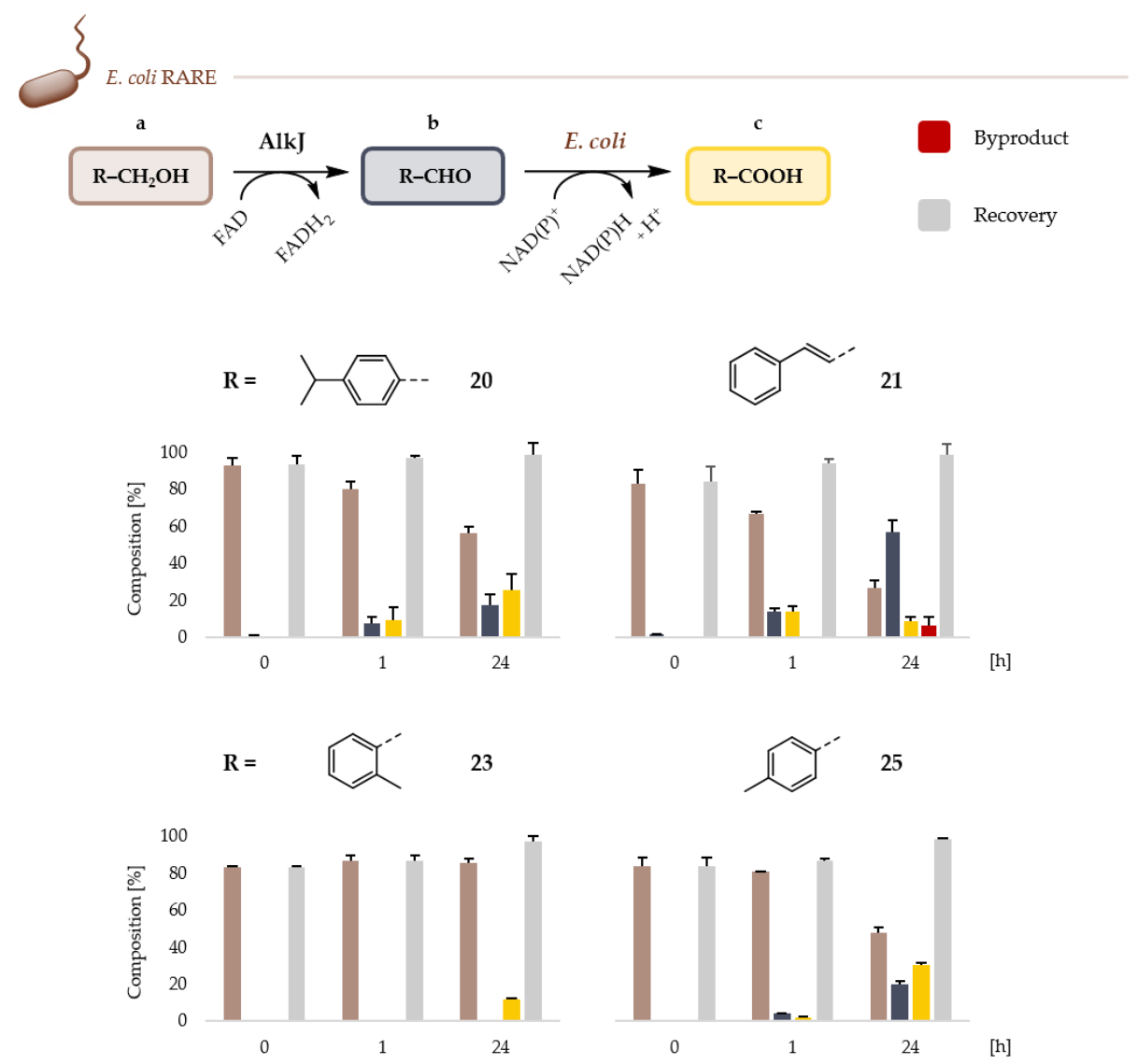

Figure 4. Extended scope of AlkJ towards aromatic compounds. Oxidation of the new alcohol substrates 20-21a, 23a and 25a to the corresponding aldehydes (b) by AlkJ and overoxidation to CAs (c) by endogenous enzymes. In biotransformations of 21a, 3-phenyl propanol (22a) was detected as byproduct. Experiments were performed in RCs of E. coli RARE $\left(\mathrm{OD}_{600} \approx 10.0\right)$ expressing AlkJ from pACYQ in the presence of $5 \mathrm{mM}$ alcohol (a) and $5 \%(v / v)$ ethanol as co-solvent. Sampling: $0 \mathrm{~h}$ (after the addition of substrate and mixing), $1 \mathrm{~h}$ and $24 \mathrm{~h}$. Reduced recoveries attributed to low solubility in resting cell medium (RCM) and/or volatility of compounds; $100 \%$ recovery represents the complete retrieval of the amount of substance added. GC yields presented as mean values + SD (\%) of biological replicates $(n=3)$.

GC/FID analysis confirmed the AlkJ-catalyzed production of $\mathbf{2 0 - 2 1 b}$ and $\mathbf{2 5 b}$ from the corresponding aromatic alcohols with the highest GC yield for the industrially important $\mathbf{2 1 b}$ (56.5 $\pm 6.8 \%$ after $24 \mathrm{~h}$ ). Besides the overoxidized cinnamic acid (21c; $8.5 \pm 2.2 \%$ ), 3-phenyl propanol (22a; $6.5 \pm 4.2 \%$ )-lacking the $\mathrm{C}=\mathrm{C}$ bond in the side chain-could be detected; both are expected byproducts formed by endogenous host enzymes $[15,59,60]$. Further, the tested aromatic alcohols with aliphatic substituents in the para-position were utilized by AlkJ; $\mathbf{2 0 b}$ and 4-methylbenzaldehyde (25b) were readily produced, whereas the ortho-substituted 23a only showed a low level of conversion (Figure 4). The same preference for aromatic aldehydes with aliphatic substituents in the para-position is indicated for LuxAB, based on the HT assay results (Figure 3D). This prediction was substantiated by biotransformations in RCs of E. coli RARE expressing $\mathrm{CAR}_{M m} / \mathrm{PPT}_{N i}$ : The ortho-, meta- and para-substituted 23-25c were reduced to 2-methylbenzaldehyde (23b), 3-methylbenzaldehyde (24b) and 25b, respectively (Figure S8). Since $\mathbf{2 3 b}$ and $\mathbf{2 4 b}$ are poor substrates for LuxAB, they could not be unambiguously detected in the HT assay (Figure 3D). 


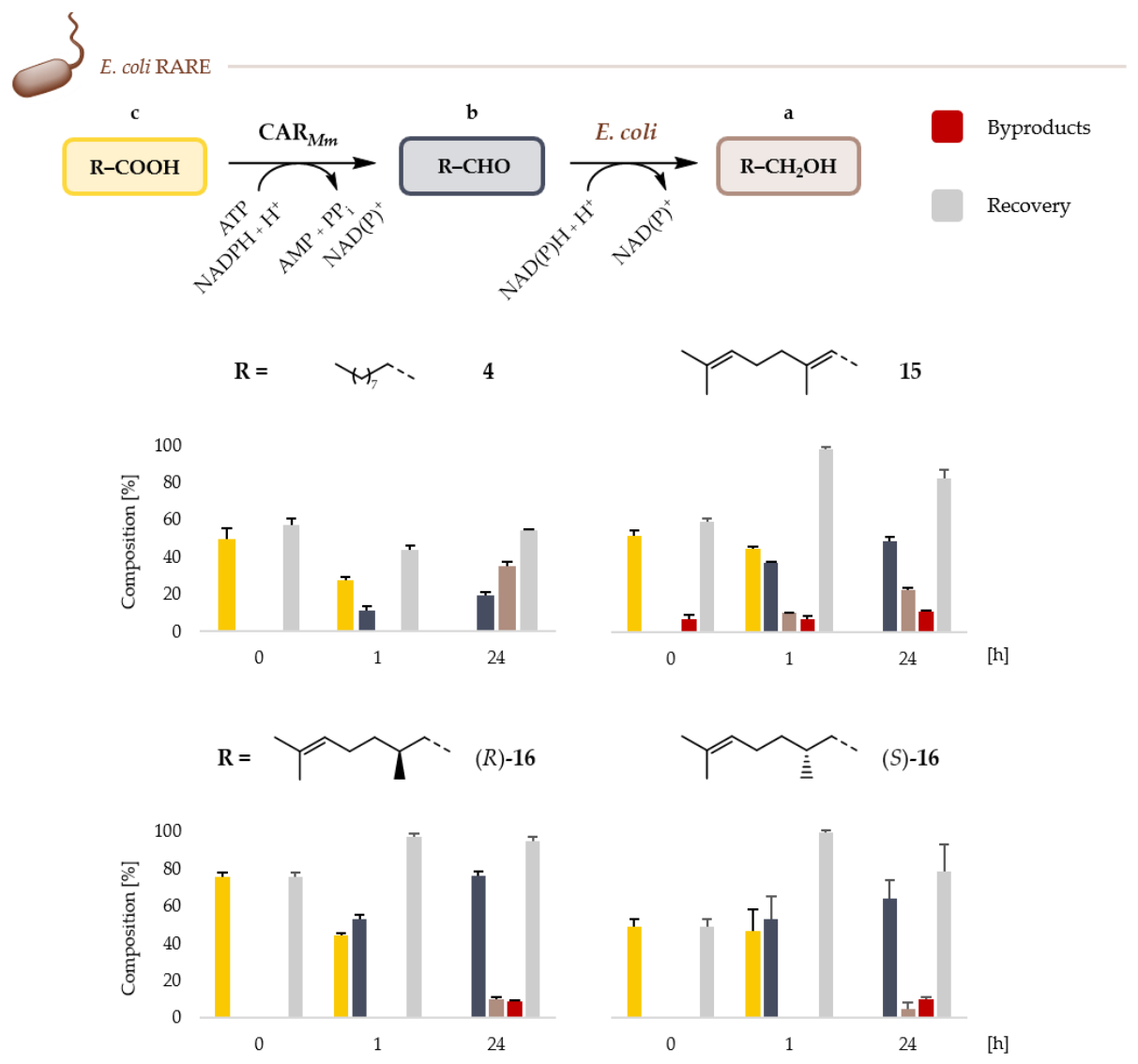

Figure 5. Production of (monoterpene) aldehydes by $\mathrm{CAR}_{M m}$ and transformation in vivo. Reduction of 15-16c to the target aldehydes (b) and further reduction to the corresponding alcohols (a) by endogenous ADHs. Other byproducts indicate enoate reductase (ERED) activity, which is omitted for clarity as well as $\mathrm{PPT}_{N i}$ for the posttranslational modification of $\mathrm{CAR}_{M m}$. The reduction of $4 \mathrm{c}$ was used as positive control. The exact compositions including byproducts are given in Table S11. Experiments were performed in RCs of E. coli RARE $\left(\mathrm{OD}_{600} \approx 10.0\right)$ expressing $\mathrm{CAR}_{M m} / \mathrm{PPT}_{N i}$ from pACYCDuet-1 in the presence of $5 \mathrm{mM} \mathrm{CA} \mathrm{(c)} \mathrm{and} \mathrm{5 \%}(v / v)$ ethanol as organic co-solvent. Sampling: $0 \mathrm{~h}$ (after the addition of substrate and mixing), $1 \mathrm{~h}$ and $24 \mathrm{~h}$; reduced recoveries attributed to low solubility in RCM, volatility and/or metabolization of compounds. GC yields presented as mean values $+\mathrm{SD}(\%)$ of biological replicates $(n=3)$.

GC/FID analysis also confirmed the enzymatic production of value-added monoterpene aldehydes in vivo. $\mathrm{CAR}_{\mathrm{Mm}}$ efficiently converted geranic acid (15c) and the two enantiomers of citronellic acid- $(R)$ - and $(S)-\mathbf{1 6} \mathbf{c}$ - to the corresponding aldehydes. The reduction of $\mathbf{1 5 c}$ yielded $49.0 \pm 2.7 \%$ of the desired $15 b$ and the over-reduced $15 a(22.9 \pm 1.1 \%)$. Since E. coli RARE was engineered to specifically increase the persistence of aromatic aldehydes, the reduction of other aldehyde classes can be expected [21]. Furthermore, 16b, which lacks the proximal $\mathrm{C}=\mathrm{C}$ double bond, was detected $(11.0 \pm 0.8 \%)$ after $24 \mathrm{~h}$, (Figure 5). As before, these byproducts are produced by host enzymatic activities $[9,15,20,59-61]$.

Similarly, the reductions of $(R)$ - and $(S)-16 c$ yielded $(R)-16 b(76.1 \pm 2.2 \%)$ and $(S)-$ $\mathbf{1 6 b}(63.9 \pm 10.3 \%)$, as well as the over-reduced 16a and the over-oxidized 15c (Figure 5; see also: Table S11). Again, these results substantiated the extended aldehyde detection scope of LuxAB (Figure 3C). AlkJ showed low activity towards (R)- and (S)-16a, yielding $11.8 \pm 1.2 \%(R)-\mathbf{1 6 b}$ and $2.4 \pm 0.2 \%(S)-\mathbf{1 6 b}$, respectively. Interestingly, only $\mathbf{1 5 c}-$ not 16c-was detected as the byproduct in low amounts (Figure 6A; Table S12). Under the same conditions, AlkJ efficiently oxidized 15a, exclusively yielding $83.8 \pm 1.0 \%$ of the important aroma compound $\mathbf{1 5 b}$ after $24 \mathrm{~h}$; the overoxidized 15c was not detected (Figure 6A). Like the flavin adenine dinucleotide (FAD)-dependent ADH AlkJ, potential endogenous 
EREDs such as $N$-ethylmaleimide reductase [62] or 2,4-dienoyl-CoA reductase [63] are flavoproteins. That the reduction of the proximal double bond was not observed in biotransformations of 15a could be explained by the competition for FAD and/or the depletion of the precursor flavin mononucleotide (FMN) [58]. This bottleneck might also be the cause for the only slightly increased amounts of CAs in biotransformations employing RCs co-expressing AlkJ and the FMN-dependent MO LuxAB (Figure 6; see also Figure 1). This does not necessarily contradict the high bioluminescence signals of AlkJ/LuxAB under HT assay conditions since luciferases are very good photoemitters in terms of quantum yield and the detection is highly sensitive [64]. Starting from 4a, $(R)-\mathbf{1 6 a}$ or $(S)-\mathbf{1 6 a}$, the amounts of the observed overoxidation products increased 1.3-fold (4c), 1.4-fold (15c) and 2.1-fold (15c), respectively, in cells co-expressing AlkJ and LuxAB; 15c could be detected in traces in biotransformations starting from 15a (Figure 6B), which was not observed in reactions employing AlkJ alone (Figure 6A). Although subtle, these findings suggest a new enzymatic cascade transforming alcohols into carboxylates via two steps in living cells.

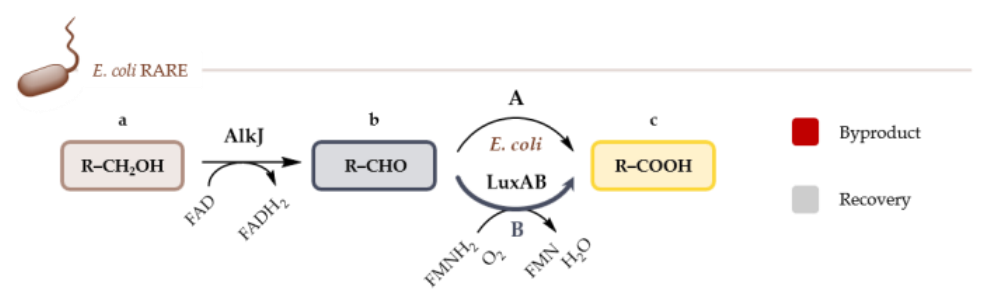

A
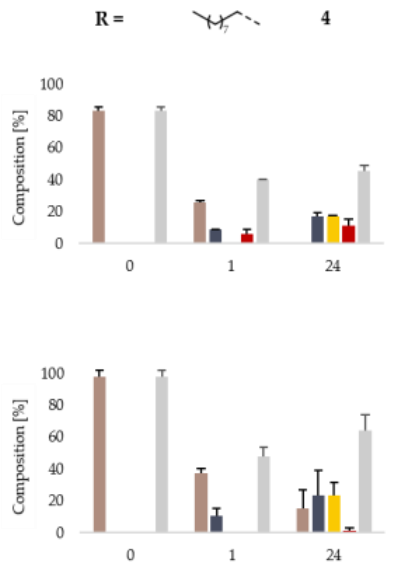
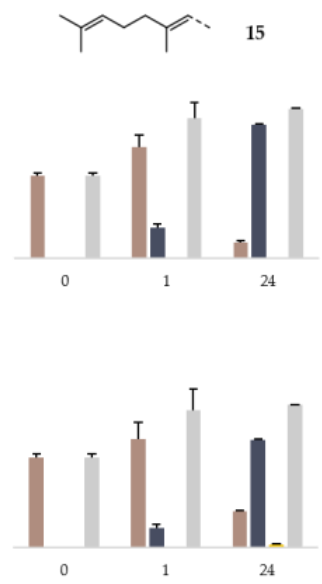
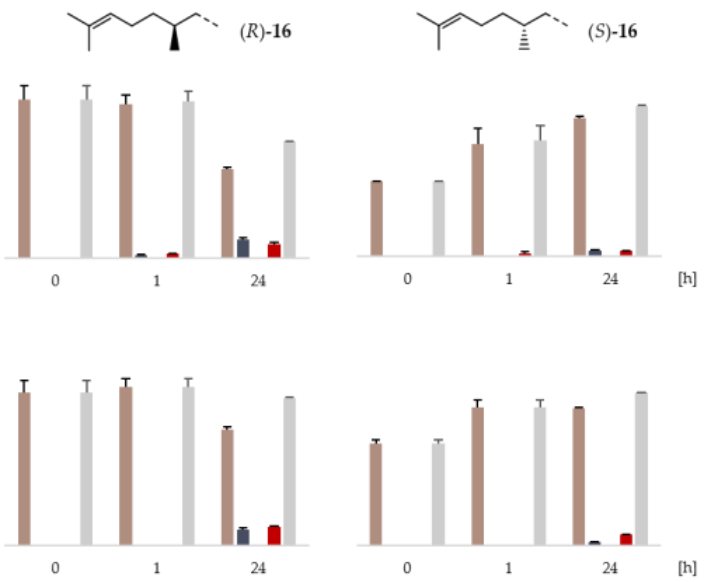

Figure 6. Production of (monoterpene) aldehydes by AlkJ and transformation by LuxAB in vivo. Oxidation of 15-16a to the desired aldehydes (b) and further oxidation to the corresponding CAs (c) by (A) endogenous E. coli enzymes and (B) LuxAB. The oxidation of $4 \mathbf{a}$ was used as positive control and yielded byproducts originating from pathways for the metabolization of fatty acids [65,66]. The exact compositions including byproducts are given in Table S12. Experiments were performed in RCs of E. coli RARE $\left(\mathrm{OD}_{600} \approx 10.0\right)$ expressing $(\mathbf{A})$ only AlkJ or $(\mathbf{B})$ AlkJ and LuxAB from pAYCQ and pLuxAB, respectively, in the presence of $5 \mathrm{mM}$ alcohol (a) and 5\% (v/v) ethanol as organic co-solvent. Sampling: $0 \mathrm{~h}$ (after the addition of substrate and mixing), $1 \mathrm{~h}$ and $24 \mathrm{~h}$; reduced recoveries attributed to low solubility in RCM, volatility and/or metabolization of compounds. GC yields presented as mean values $+\mathrm{SD}(\%)$ of biological replicates $(n \geq 2)$.

\section{Discussion and Conclusions}

The continuously expanding number of new biocatalysts from both natural resources and protein engineering endeavors demands for tools for their rapid characterization $[67,68]$. In this context, genetically encoded biosensor systems have been embraced since they translate the detection of small molecules into a measurable output such as fluorescence or bioluminescence $[34,69]$.

In this study, the LuxAB system from P. luminescens, emitting bioluminescence through the oxidation of aldehydes to the corresponding CAs [45], was successfully implemented in E. coli RARE (Figure 1). This effort led to the establishment of a simple HT assay 
that revealed the capability of LuxAB to detect structurally diverse aldehydes, including monoterpene and aromatic aldehydes in living cells (Figure 2). The versatility of the assay was demonstrated by the screening of three different microbial oxidoreductases-AlkJ, CO$6_{A c}$ and $C A R_{M m}$ - against an extended substrate library, producing up to 25 industrially relevant aldehydes (Figure 3). Under HT screening conditions, both the background bioluminescence and the maximal bioluminescence signal depended on the expressed oxidoreductase. AlkJ/LuxAB yielded the highest maximal-fold increase in bioluminescence in the presence of the preferred aliphatic substrates (e.g., >9000-fold for 4a). In comparison, $\mathrm{LuxAB} / \mathrm{CAR}_{M m}$ and LuxAB/CO-6 ${ }_{A c}$ only increased the maximal bioluminescence $>900$ fold $(4 \mathbf{c})$ and $\approx 100$-fold (3a), respectively (Figure $3 B$ ). These deviations are not solely based on the substrate preferences of the target oxidoreductase but can be explained by their distinct enzymatic properties including the acceptance of intracellular fatty acids as substrates by $\mathrm{CAR}_{M m}$, increasing the background bioluminescence or the production of $\mathrm{H}_{2} \mathrm{O}_{2}$ by the mutant choline oxidase $\mathrm{CO}-6_{A c}$, resulting in decreased cellular viability. The introduction of an XCO value sufficed to address varying backgrounds and allowed the confirmation of the substrate ranges of AlkJ, CAR ${ }_{M m}$ and $\mathrm{CO}-6_{A c}$ in vivo. The latter only had been assessed before in vitro [51]. Furthermore, new substrates for the ADH AlkJ and $\mathrm{CAR}_{M m}$ could be identified and confirmed in whole-cell transformations and subsequent GC/FID analysis. Biotransformations also revealed the limits of the detection scope of the LuxAB biosensor system: Although the aromatic aldehydes 23-24b were readily produced by $\mathrm{CAR}_{M m}$ (Figure S8), for example, they are poor substrates for LuxAB and could not be efficiently detected under HT assay conditions; $23 \mathbf{b}$ was also produced from 23a by AlkJ previously [15]. On the other hand, poor substrates for a given oxidoreductase yielding low amounts of aldehydes that are well-accepted by LuxAB might emit high bioluminescence, consequently, suggesting a deceptive oxidoreductase scope.

In addition to $\mathbf{2 0 b}, \mathbf{2 3 b}$ and $25 \mathrm{~b}$, AlkJ yielded the flavorant cinnamaldehyde $(\mathbf{2 1 b})$ in satisfying yields. In a cascade reaction catalyzed by endogenous host enzymes, 20b, 23b and $\mathbf{2 5 b}$ were oxidized to the corresponding CAs (Figure 4). CAR $\mathrm{C}_{M m}$ efficiently reduced the newly identified carboxylate substrates $(R)$ - and $(S)$-16c to the corresponding monoterpenoid aldehydes in $76.1 \pm 2.2 \%$ and $63.9 \pm 10.3 \%$ GC yields, respectively (Figure 5). Citronellal (16b) is not only used as a scent, but has insect repellent and antifungal properties [70,71]. Excitingly, the AlkJ-catalyzed oxidation of 15a exclusively formed 15b (>80\% GC yield; Figure 6A), offering a biocatalytic alternative to chemical oxidation procedures [72] and enabling combinations with other enzymatic transformations, for example, the XenAmediated reduction of the proximal $C=C$ double bond, yielding $16 \mathbf{b}$, as suggested by Richardson and co-workers [61]. Citral (15b) is widely used in perfumes, as mosquito repellant [73] and is an important precursor for other terpenes [74] and carotenoids including vitamin A [75]. Albeit low, this study also confirmed the $\mathrm{MO}$ activity of LuxAB in a cascade set-up with AlkJ, indicated by the detectable increase in carboxylate products (Figure 6B).

In summary, the genetically-encoded LuxAB proved to be a versatile biosensor for the HT detection of structurally divers aldehyde compounds, without the need of undesirable auxiliary chemicals such as ABAOs. Additionally, the fast detection of aldehydes by the enzyme-based biosensor is advantageous to TF-based systems. The applicability of the HT assay was demonstrated by the extension of the substrate scopes of different oxidoreductases and the bio-based production of monoterpene aldehydes, amongst others. These findings will facilitate the identification and characterization of novel biocatalysts in the future, advance the enzymatic preparation of industrial aldehydes and point towards their diversification through (LuxAB-based) microbial cell factories.

\section{Materials and Methods}

\subsection{General Information}

Chemicals, reagents and reference compounds were purchased from Sigma-Aldrich (Buchs, Switzerland), Roth (Karlsruhe, Germany) or TCI Chemicals (Tokyo, Japan) and used without further purification, unless stated otherwise. Table S13 provides an overview 
of all compounds (1-25) analyzed in this study. Solvents (GC grade) were purchased from Sigma-Aldrich or J.T. Baker (Schwerte, Germany).

The following E. coli laboratory strains were purchased from Thermo Scientific/ Invitrogen (Darmstadt, Germany): BL21 (DE3), DH5 $\alpha$ and TOP10. E. coli RARE was acquired from the Prather group [21].

Unless stated otherwise, chemically competent $E$. coli cells were produced by wellestablished protocols using $\mathrm{CaCl}_{2}(0.1 \mathrm{M})$ and transformed with plasmid DNA (25-100 ng. $\mu \mathrm{L}^{-1}$ ) by heat-shock at $42{ }^{\circ} \mathrm{C}$ for $45 \mathrm{~s}$ (see: Supplementary Materials). Recovery was performed in SOC medium ( $2 \%$ tryptone, $0.5 \%$ yeast extract, $10 \mathrm{mM} \mathrm{NaCl}, 2.5 \mathrm{mM}$ $\mathrm{KCl}, 10 \mathrm{mM} \mathrm{MgCl}_{2}, 10 \mathrm{mM} \mathrm{MgSO}_{4}$ and $20 \mathrm{mM}$ glucose) at $37^{\circ} \mathrm{C}$ with vigorous shaking. For efficient transformation of E. coli RARE, plasmids were passed through E. coli $\mathrm{DH} 5 \alpha$ before. Selection of transformants was performed in lysogeny broth (LB) medium ( $25 \mathrm{~g} \cdot \mathrm{L}^{-1}$; Sigma-Aldrich) or on LB agar plates containing 1.5\% agar-agar (Roth) in the presence of the appropriate antibiotic(s) (final concentration): chloramphenicol $\left(34 \mu \mathrm{g} \cdot \mathrm{mL}^{-1}\right)$, kanamycin $\left(50 \mu \mathrm{g} \cdot \mathrm{mL}^{-1}\right)$ and streptomycin $\left(25 \mu \mathrm{g} \cdot \mathrm{mL}^{-1}\right)$. Only half the concentration of antibiotics was used for the selection and subsequent cultivation of strains harboring two plasmids. Co-transformants were produced by transforming chemically competent $E$. coli RARE harboring pLuxAB with the desired oxidoreductase-coding plasmid as described above.

\subsection{Plasmid Assemblies by Sequence- and Ligation-Independent Cloning (SLIC) Techniques}

Standard DNA oligonucleotides (desalted) were ordered from Thermo Fisher Scientific/Invitrogen and dissolved in nuclease-free water (Invitrogen). The resulting stock solutions $(100 \mu \mathrm{M})$ were further diluted and used as primers for PCRs $(5 \mu \mathrm{M})$ or Sanger sequencing $(10 \mu \mathrm{M})$. PCRs were performed in a thermal cycler (Biometra TAdvanced, Analytik Jena, Jena, Germany) with $\mathrm{Pfu}^{+}$or OptiTaq DNA polymerase (Roboklon, Berlin, Germany) or $\mathrm{Q} 5{ }^{\circledR}$ high-fidelity (Q5 ${ }^{\circledR}$-HF) DNA polymerase (New England Biolabs, Frankfurt/Main, Germany); premixed dNTPS (10 mM each) were purchased from Roth. Other enzymes for the manipulation of DNA were purchased from Thermo Fisher Scientific or New England Biolabs.

PCR products were purified with QIAquick PCR \& Gel Cleanup Kit (QIAGEN, Hilden, Germany) and plasmid DNA isolated with innuPREP Plasmid Mini Kit 2.0 (Analytik Jena) as instructed by the suppliers. DNA concentration was determined by NanoDrop ${ }^{\mathrm{TM}}$ 2000 spectrophotometer (Thermo Fisher Scientific, Darmstadt, Germany). Sanger sequencing was performed by Eurofins Genomics (Ebersberg, Germany).

In this study, plasmids were assembled from two linear DNA fragments via homologous overhangs attached by PCR, following adapted protocols from Li et al. [76] or Wiesinger et al. [50]. The latter employed a seamless and ligation-independent cloning extract (SLiCE) that was prepared according to Zhang et al. from E. coli TOP10 cultures [49]. Primer sequences and templates are given in Tables S9 and S10, respectively, in the Supplementary Materials. Optimal annealing temperatures $\left(T_{a}\right)$ were determined by gradient PCR $\left(45-65^{\circ} \mathrm{C}\right)$, unless stated otherwise. Composition of PCR mixtures and construct-specific thermal cycle conditions are given in the Supplementary Materials.

For the construction of $\mathrm{pCDFduo/luxAB}$, herein referred to as $\mathrm{pLuxAB}$, the DNA fragment encoding the $l u x A B$ subunits was amplified from pAK400c/iluxAB_Cm ${ }^{r}$ [48] with the primer pair LuxA_T5 F/LuxB R, which introduced flanking 15 bp-overhangs complementary to the target $\mathrm{pCDFDuet}-1$ vector for the subsequent assembly, and $\mathrm{Pfu}^{+}$ $\left(\mathrm{T}_{\mathrm{a}}=45.0^{\circ} \mathrm{C}\right.$; Figure $\left.\mathrm{S} 1\right)$. The $\mathrm{pCDF}$ backbone was amplified with primers $\mathrm{pCDF} F / \mathrm{R}$ and OptiTaq $\left(\mathrm{T}_{\mathrm{a}}=48.0^{\circ} \mathrm{C}\right.$ as calculated from the melting temperature of primers; Figure S1). The correct assembly by SLiCE was confirmed by Sanger sequencing of isolated plasmid DNA from single colonies of E. coli BL21 (DE3) transformants selected on LB agar plates supplemented with streptomycin.

For the construction of $\mathrm{pAYCQ/alkJ,} \mathrm{the} \mathrm{DNA} \mathrm{fragment} \mathrm{harboring} \mathrm{the} \mathrm{alkJ} \mathrm{fragment}$ was amplified from pGEc47 [77] with the primer pair AlkJ F/R, introducing 15 bp-overhangs complementary to the target pACYC vector, and $\mathrm{Pfu}^{+}\left(\mathrm{T}_{\mathrm{a}}=48.6{ }^{\circ} \mathrm{C}\right.$; Figure $\left.\mathrm{S} 2\right)$. The pACYC 
backbone was amplified with the primers pACYC F/pACYC-2 R and OptiTaq $\left(\mathrm{T}_{\mathrm{a}}=48.6^{\circ} \mathrm{C}\right.$; Figure S2). Purified DNA fragments were processed and incubated with the SLiCE. Subsequently, chemically competent $E$. coli TOP10 cells were transformed with the assembly mixtures. Colonies were selected on LB agar plates containing chloramphenicol the next day. Sanger sequencing of isolated plasmid DNA revealed a truncated ORF of the alkJ gene in all samples (see also: Table S10). The ORF was restored using the $\mathrm{Q} 5^{\circledR}$ Site-Directed Mutagenesis Kit (New England Biolabs) with the primer pair AJQ5 F/R $\left(\mathrm{T}_{\mathrm{a}}=61.0^{\circ} \mathrm{C}\right.$ as calculated by the NEBaseChange ${ }^{\mathrm{TM}}$ tool available from: http:/ / nebasechanger.neb.com/ (accessed on 8 September 2019) and following the instructions of the supplier. Finally, the completeness of the alkJ ORF was confirmed by Sanger sequencing.

For the construction of pACYCDuet-1/(car $\mathrm{Mm}$ :ppt ${ }_{N i}$, chemically competent $E$. coli TOP10 cells were directly transformed with the assembly mixture (molar ratio of insert to backbone of 3:1) according to Li et al. [76] after DpnI digestion. Therefore, the $p p t_{N i}$ insert had been amplified from $\mathrm{pCDF} / p p t_{N i}$ with the primer pair $\mathrm{Npt} F / \mathrm{R}$ and $\mathrm{Q} 5{ }^{\oplus}-\mathrm{HF}$ $\left(\mathrm{T}_{\mathrm{a}}=57.0^{\circ} \mathrm{C}\right.$; Figure S3). The pACYCDuet-1 backbone harboring the car $_{M m}$ gene was amplified with the primers pCAR_Npt F/R and $Q 5^{\circledR}-\mathrm{HF}\left(\mathrm{T}_{\mathrm{a}}=64.0^{\circ} \mathrm{C}\right.$; Figure $\left.\mathrm{S} 3\right)$. The correct assembly was confirmed by Sanger sequencing of isolated plasmid DNA from single colonies of transformants selected on LB agar plates supplemented with chloramphenicol.

The gene encoding the choline oxidase variant was codon-optimized for the expression in E. coli, synthesized and subcloned into pET28a by the BioCat GmbH (Heidelberg, Germany).

\subsection{Standard Conditions for Enzyme Production and the Preparation of Resting Cells (RCs)}

Protein production (AlkJ, $\mathrm{CAR}_{M m} / \mathrm{PPT}_{N i}, \mathrm{CO}-6_{A c}$ and LuxAB) was performed in E. coli RARE transformants cultivated in auto-induction medium (AIM; $2.5 \%$ LB medium, $1 \mathrm{mM}$ $\mathrm{MgSO}_{4}, 25 \mathrm{mM}\left(\mathrm{NH}_{4}\right)_{2} \mathrm{SO}_{4}, 50 \mathrm{mM} \mathrm{KH}_{2} \mathrm{PO}_{4}, 50 \mathrm{mM} \mathrm{Na}_{2} \mathrm{HPO}_{4}, 5 \%$ glycerol, $0.5 \%$ glucose and $2 \% \alpha$-lactose) adapted from Studier [78]. Briefly, a single colony of the desired strain was grown in LB medium containing the appropriate antibiotic(s) at $37^{\circ} \mathrm{C}(180 \mathrm{rpm})$ for $12-16 \mathrm{~h}$. AIM supplemented with antibiotic(s) was inoculated with $0.2 \%(v / v)$ preculture in baffled flasks and incubated in Infors HT Multitron incubator shakers (Bottmingen, Switzerland) at $37^{\circ} \mathrm{C}(180 \mathrm{rpm})$ for $4-6 \mathrm{~h}(6 \mathrm{~h}$ for co-transformants, $5 \mathrm{~h}$ for pLuxAB transformants and $4 \mathrm{~h}$ for all others). Enzyme production was performed at $20^{\circ} \mathrm{C}(150 \mathrm{rpm})$ for $16-20 \mathrm{~h}$. The optical density at $600 \mathrm{~nm}\left(\mathrm{OD}_{600}\right)$ of cultures was determined with a UV1280 spectrophotometer (Shimadzu, Kyoto, Japan). Cells were harvested by centrifugation $\left(6000 \times g, 4{ }^{\circ} \mathrm{C}\right)$ for $20 \mathrm{~min}$ using a Heraeus Fresco 17 centrifuge or a Heraeus Labofuge 400R (Thermo Fisher Scientific). The cell pellet was resuspended in RCM (22 mM KH $\mathrm{PO}_{4}$, $42 \mathrm{mM} \mathrm{Na}_{2} \mathrm{HPO}_{4}, 8.56 \mathrm{mM} \mathrm{NaCl}, 1 \mathrm{mM} \mathrm{MgSO}, 1 \mathrm{mM} \mathrm{CaCl}_{2}$ and $1 \%$ glucose) until an $\mathrm{OD}_{600} \approx 10.0$ was reached. RCs were used on the day of preparation.

Protein expression was confirmed by $12.5 \%(\omega / v)$ SDS-PAGE analysis of whole-cell samples normalized to $\mathrm{OD}_{600}=7.0$, using the Mini-PROTEAN electrophoresis system (Bio-Rad, Feldkirchen, Germany) and following standard protocols (e.g., [50]). Gels were stained with InstantBlue ${ }^{\mathrm{TM}}$ Protein Stain (Expedeon, Heidelberg, Germany).

\subsection{LuxAB-Based HT Screening of Enzymes In Vivo}

RCs co-expressing LuxAB and the enzyme of interest were prepared as described above. To $198 \mu \mathrm{L}$ RCs $\left(\mathrm{OD}_{600} \approx 10.0\right)$ per well, $2 \mu \mathrm{L}$ stock solution of the target substrate (0.1 $\mathrm{M}$ in dimethyl sulfoxide or ethanol) were added to a final concentration of $1 \mathrm{mM}$ substrate $\left(\mathrm{V}_{\text {total }}=200 \mu \mathrm{L}\right.$ containing $1 \%(v / v)$ organic co-solvent) in 96-well plates (flat bottom, black polystyrene [50,65,76]; Greiner Bio-One, Frickenhausen, Germany). It was mixed gently and the bioluminescence measured immediately on a Varioskan ${ }^{\mathrm{TM}}$ LUX multimode plate reader (Thermo Fisher Scientific). The change in bioluminescence was followed at $25^{\circ} \mathrm{C}$ for up to $1 \mathrm{~h}$.

To assess the fold increase in bioluminescence above background $\left(b_{\mathbf{x}}\right)$ caused by the enzymatic production of aldehydes from substrates, the blank-corrected bioluminescence signal at the corresponding time point $\left(t_{\mathrm{x}}\right)$ was divided by the bioluminescence signal 
before substrate addition ( $\mathrm{t}_{0}$; see also: Supplementary Materials). The blank value is referred to the bioluminescence in RC suspensions before the addition of any organic compound. In parallel, the increase in bioluminescence in the presence of $1 \%(v / v)$ organic co-solvent in RCs expressing LuxAB (or in combination with the oxidoreductase of interest) was monitored and the fold increase calculated as before, yielding the cut-off value. Substrate-enzyme combinations exhibiting bioluminescence greater than the cut-off value $+\mathrm{SD}$, referred to as the XCO (see also: Figure S7), were re-screened in whole-cell biotransformations expressing the corresponding oxidoreductase alone.

\subsection{Whole-Cell Biotransformations and Gas Chromatographic (GC) Analysis}

$\mathrm{RCs}\left(\mathrm{OD}_{600} \approx 10.0\right)$ expressing the oxidoreductase of interest or expressing LuxAB and AlkJ for cascade reactions were prepared as described under Section 4.3; wholecell biotransformations were performed in glass vials with screw-caps $(4 \mathrm{~mL})$ at $5 \mathrm{mM}$ substrate concentration for alcohols and carboxylates in the presence of $5 \%(\mathrm{v} / \mathrm{v})$ organic co-solvent $\left(\mathrm{V}_{\text {total }}=0.5 \mathrm{~mL}\right)$ in Infors HT Multitron incubator shakers at $25^{\circ} \mathrm{C}(220-250 \mathrm{rpm})$ for $0-24 \mathrm{~h}$. For GC analysis, samples $(100 \mu \mathrm{L})$ of the biotransformation mixtures were taken immediately after the addition of substrate and mixing $(\mathrm{t} \approx 0 \mathrm{~h}), 1 \mathrm{~h}$ and $24 \mathrm{~h}$. Unless for biotransformations involving monoterpenoid aldehydes (e.g., 15b) and related compounds [74], samples were acidified with $2 \mathrm{M} \mathrm{HCl}(10 \mu \mathrm{L})$ and extracted two times with ethyl acetate $(200 \mu \mathrm{L})$ containing $1 \mathrm{mM}$ methyl benzoate as internal standard (IS) by vortexing for $30-45 \mathrm{~s}$. It was centrifuged $\left(13,000 \times g, 4{ }^{\circ} \mathrm{C}\right)$ for $1 \mathrm{~min}$. The combined organic phases were dried over $\mathrm{Na}_{2} \mathrm{SO}_{4}$ and transferred into a GC vial with insert, capped and submitted to GC analysis. Compound identification was performed by the comparisons of retention times of commercial standards (Table S13), unless stated otherwise; quantification and calculation of GC yields were performed by standard calibrations or using relative response factors (see: Supplementary Materials).

GC analysis (GC-2010 Plus, Shimadzu) using a flame ionization detector (FID; Shimadzu) was performed on a ZB-5MSi column (length: $30 \mathrm{~m}$; inner diameter: $0.25 \mathrm{~mm}$; film thickness: $0.25 \mu \mathrm{m}$ ) from Phenomenex (Torrance, USA). GC/FID method (hydrogen, $0.96 \mathrm{~mL} \cdot \mathrm{min}^{-1}$ flow rate; injector and detector: $300{ }^{\circ} \mathrm{C}$ ): $100{ }^{\circ} \mathrm{C}$, hold $1 \mathrm{~min}, 20^{\circ} \mathrm{C}$ per min to $250^{\circ} \mathrm{C}$, hold $5 \mathrm{~min}$; total time: $13.5 \mathrm{~min}$. GC/MS analysis (GCMS-QP2010 SE, Shimadzu) was performed on the same column. GC/MS method (helium, $1.00 \mathrm{~mL} \cdot \mathrm{min}^{-1}$ flow rate; injector: $280^{\circ} \mathrm{C}$, ion source and interface: $260^{\circ} \mathrm{C}$ ): $100^{\circ} \mathrm{C}$, hold $5 \mathrm{~min}, 20^{\circ} \mathrm{C}$ per min to $250{ }^{\circ} \mathrm{C}$, hold $5 \mathrm{~min}, 20^{\circ} \mathrm{C}$ per min to $280^{\circ} \mathrm{C}$ and hold $5 \mathrm{~min}$; total time: $24.0 \mathrm{~min}$.

Supplementary Materials: The following are available online at https:/ / www.mdpi.com/article/10 .3390 / catal11080953/s1; Figure S1: DNA fragments for the assembly of pLuxAB, Figure S2: DNA fragments for the assembly of pACYC/alkJtrnc, Figure S3: DNA fragments for the assembly of pACYCDuet-1/carMm:pptNi, Figure S4: SDS-PAGE analysis of whole-cell samples, Figure S5: LuxABbased detection of aldehydes at low concentration in E. coli, Figure S6: LuxAB-based detection of aldehydes in E. coli (background and negative controls), Figure S7: Background luminescence and determination of the XCO value, Figure S8: Enzymatic reduction of toluic acids by CARMm; Table S1: PCR mixtures for the assembly of pLuxAB, Table S2: Optimized thermal cycle conditions for the assembly of pLuxAB, Table S3: PCR mixtures for the assembly of pACYC/alkJ, Table S4: Optimized thermal cycle conditions for the assembly of pACYC/alkJ, Table S5: Q5 ${ }^{\circledR}$ mutagenesis reaction mixture, Table S6: Thermal cycle conditions for $\mathrm{Q} 5^{\circledR}$ mutagenesis, Table S7: PCR mixtures for the assembly of pACYCDuet-1/carMm:pptNi, Table S8: Optimized thermal cycle conditions for the assembly of pACYCDuet-1/carMm:pptNi, Table S9: List of DNA oligonucleotides used in this study, Table S10: List of strains and plasmids used in this study, Table S11: Production of (monoterpene) aldehydes by CARMm and transformation in vivo, Table S12: Production of (monoterpene) aldehydes by AlkJ and transformation by LuxAB, Table S13: List of compounds analyzed in this study. 
Author Contributions: Conceptualization, T.B. and U.T.B.; molecular biology including cloning, K.B., T.B., S.B. and S.S.; analytical data generation, validation and interpretation, T.B., A.B., I.J.K., I.M. and H.T.; data visualization, T.B., A.B. and I.M.; writing-original draft preparation, T.B.; writingreview and editing, S.C.A., K.B., A.B., U.T.B., S.B., I.J.K., S.S. and H.T.; supervision, S.C.A., T.B., K.B. and U.T.B.; project administration, T.B. and U.T.B.; funding acquisition, T.B., U.T.B. and I.J.K.; additional resources, S.C.A. and U.T.B. All authors have read and agreed to the published version of the manuscript.

Funding: T.B. was funded through the Erwin Schrödinger Fellowship (project no.: J4231-B21) granted by the Austrian Science Fund (FWF). I.J.K. was funded by the National Research Foundation of Korea (NRF-2020R1A6A3A03039153). Research was supported by the Federal Ministry of Food and Agriculture (BMEL; FKZ 22001617), Germany.

Data Availability Statement: Analytical data supporting the reported results are available in the manuscript, the Supplementary Materials and from the authors upon request.

Acknowledgments: The authors would like to thank B. Bühler (TU Dortmund, Germany) for gifting the pGEc47 cosmid and K.L.J. Prather (Massachusetts Institute of Technology, USA) for donating the E. coli RARE strain. The Symrise AG (Holzminden, Germany) kindly provided the genes encoding the enzymes $\mathrm{CAR}_{M m}$ and $\mathrm{PPT}_{\mathrm{Ni}}$. We would like to thank M. Winkler (acib GmbH, Graz, Austria) for valuable discussion and proofs on the manuscript. Administrative support was provided by A. Eisner (University of Greifswald, Germany) and P. Corr (Albert Einstein College of Medicine, USA). Financial support and funding are greatly acknowledged. Open Access Funding by the Austrian Science Fund (FWF).

Conflicts of Interest: The authors declare no conflict of interest.

\section{References}

1. Dabirian, Y.; Gonçalves Teixeira, P.; Nielsen, J.; Siewers, V.; David, F. FadR-based biosensor-assisted screening for genes enhancing fatty acyl-CoA pools in Saccharomyces cerevisiae. ACS Synth. Biol. 2019, 8, 1788-1800. [CrossRef]

2. Lehtinen, T.; Efimova, E.; Santala, S.; Santala, V. Improved fatty aldehyde and wax ester production by overexpression of fatty acyl-CoA reductases. Microb. Cell Fact. 2018, 17, 19. [CrossRef]

3. Xu, P.; Li, L.; Zhang, F.; Stephanopoulos, G.; Koffas, M. Improving fatty acids production by engineering dynamic pathway regulation and metabolic control. Proc. Natl. Acad. Sci. USA 2014, 111, 11299-11304. [CrossRef] [PubMed]

4. Kunjapur, A.M.; Prather, K.L.J. Development of a Vanillate Biosensor for the Vanillin Biosynthesis Pathway in E. coli. ACS Synth Biol. 2019, 8, 1958-1967. [CrossRef] [PubMed]

5. Siedler, S.; Khatri, N.K.; Zsohár, A.; Kjærbølling, I.; Vogt, M.; Hammar, P.; Nielsen, C.F.; Marienhagen, J.; Sommer, M.O.A.; Joensson, H.N. Development of a bacterial biosensor for rapid screening of yeast p-coumaric acid production. ACS Synth. Biol. 2017, 6, 1860-1869. [CrossRef]

6. Alvarez-Gonzalez, G.; Dixon, N. Genetically encoded biosensors for lignocellulose valorization. Biotechnol. Biofuels 2019, 12, 1-14. [CrossRef]

7. Luo, X.; Reiter, M.A.; D’Espaux, L.; Wong, J.; Denby, C.M.; Lechner, A.; Zhang, Y.; Grzybowski, A.; Harth, S.; Lin, W.; et al. Complete biosynthesis of cannabinoids and their unnatural analogues in yeast. Nat. Cell Biol. 2019, 567, 123-126. [CrossRef] [PubMed]

8. Meadows, A.L.; Hawkins, K.M.; Tsegaye, Y.; Antipov, E.; Kim, Y.; Raetz, L.; Dahl, R.H.; Tai, A.; Mahatdejkul-Meadows, T.; Xu, L.; et al. Rewriting yeast central carbon metabolism for industrial isoprenoid production. Nat. Cell Biol. 2016, 537, 694-697. [CrossRef] [PubMed]

9. Kunjapur, A.M.; Prather, K.L.J. Microbial Engineering for Aldehyde Synthesis. Appl. Environ. Microbiol. 2015, 81, 1892-1901. [CrossRef]

10. Atsumi, S.; Hanai, T.; Liao, J. Non-fermentative pathways for synthesis of branched-chain higher alcohols as biofuels. Nat. Cell Biol. 2008, 451, 86-89. [CrossRef] [PubMed]

11. Kaehne, F.; Buchhaupt, M.; Schrader, J. A recombinant $\alpha$-dioxygenase from rice to produce fatty aldehydes using E. coli. Appl. Microbiol. Biotechnol. 2011, 90, 989-995. [CrossRef]

12. Butler, N.; Kunjapur, A.M. Carboxylic acid reductases in metabolic engineering. J. Biotechnol. 2020, 307, 1-14. [CrossRef]

13. Qu, G.; Guo, J.; Yang, D.; Sun, Z. Biocatalysis of carboxylic acid reductases: Phylogenesis, catalytic mechanism and potential applications. Green Chem. 2018, 20, 777-792. [CrossRef]

14. Napora-Wijata, K.; Strohmeier, G.A.; Winkler, M. Biocatalytic reduction of carboxylic acids. Biotechnol. J. 2014, 9, 822-843. [CrossRef] [PubMed]

15. Bayer, T.; Milker, S.; Wiesinger, T.; Winkler, M.; Mihovilovic, M.D.; Rudroff, F. In Vivo Synthesis of Polyhydroxylated Compounds from a "Hidden Reservoir" of Toxic Aldehyde Species. ChemCatChem 2017, 9, 2919-2923. [CrossRef] 
16. Wu, S.; Zhou, Y.; Wang, T.; Too, H.-P.; Wang, D.I.C.; Li, Z. Highly regio- and enantioselective multiple oxy- and aminofunctionalizations of alkenes by modular cascade biocatalysis. Nat. Commun. 2016, 7, 11917. [CrossRef]

17. Schrewe, M.; Julsing, M.K.; Lange, K.; Czarnotta, E.; Schmid, A.; Bühler, B. Reaction and catalyst engineering to exploit kinetically controlled whole-cell multistep biocatalysis for terminal FAME oxyfunctionalization. Biotechnol. Bioeng. 2014, 111, 1820-1830. [CrossRef]

18. Rodriguez, G.M.; Atsumi, S. Isobutyraldehyde production from Escherichia coli by removing aldehyde reductase activity. Microb. Cell Fact. 2012, 11, 90. [CrossRef]

19. He, A.; Li, T.; Daniels, L.; Fotheringham, I.; Rosazza, J.P.N. Nocardia sp. Carboxylic Acid Reductase: Cloning, Expression, and Characterization of a New Aldehyde Oxidoreductase Family. Appl. Environ. Microbiol. 2004, 70, 1874-1881. [CrossRef]

20. Rodriguez, G.M.; Atsumi, S. Toward aldehyde and alkane production by removing aldehyde reductase activity in Escherichia coli. Metab. Eng. 2014, 25, 227-237. [CrossRef]

21. Kunjapur, A.M.; Tarasova, Y.; Prather, K.L.J. Synthesis and Accumulation of Aromatic Aldehydes in an Engineered Strain of Escherichia coli. J. Am. Chem. Soc. 2014, 136, 11644-11654. [CrossRef] [PubMed]

22. Markel, U.; Essani, K.D.; Besirlioglu, V.; Schiffels, J.; Streit, W.R.; Schwaneberg, U. Advances in ultrahigh-throughput screening for directed enzyme evolution. Chem. Soc. Rev. 2020, 49, 233-262. [CrossRef]

23. Santos-Zavaleta, A.; Sánchez-Pérez, M.; Salgado, H.; Velázquez-Ramírez, D.A.; Gama-Castro, S.; Tierrafría, V.H.; Busby, S.J.W.; Aquino, P.; Fang, X.; Palsson, B.O.; et al. A unified resource for transcriptional regulation in Escherichia coli K-12 incorporating high-throughput-generated binding data into RegulonDB version 10.0. BMC Biol. 2018, 16, 91. [CrossRef]

24. Jang, S.; Jang, S.; Xiu, Y.; Kang, T.J.; Lee, S.-H.; Koffas, M.A.G.; Jung, G.Y. Development of Artificial Riboswitches for Monitoring of Naringenin In Vivo. ACS Synth. Biol. 2017, 6, 2077-2085. [CrossRef] [PubMed]

25. Lehtinen, T.; Santala, V.; Santala, S.M. Twin-layer biosensor for real-time monitoring of alkane metabolism. FEMS Microbiol. Lett. 2017, 364. [CrossRef]

26. Liu, Y.; Zhuang, Y.; Ding, D.; Xu, Y.; Sun, J.; Zhang, D. Biosensor-Based Evolution and Elucidation of a Biosynthetic Pathway in Escherichia coli. ACS Synth. Biol. 2017, 6, 837-848. [CrossRef] [PubMed]

27. Liu, D.; Evans, T.; Zhang, F. Applications and advances of metabolite biosensors for metabolic engineering. Metab. Eng. 2015, 31, 35-43. [CrossRef] [PubMed]

28. Brophy, J.A.; Voigt, C.A. Principles of genetic circuit design. Nat. Methods 2014, 11, 508-520. [CrossRef]

29. Dietrich, J.A.; McKee, A.E.; Keasling, J.D. High-Throughput Metabolic Engineering: Advances in Small-Molecule Screening and Selection. Annu. Rev. Biochem. 2010, 79, 563-590. [CrossRef] [PubMed]

30. Li, S.; Si, T.; Wang, M.; Zhao, H. Development of a synthetic malonyl-CoA sensor in Saccharomyces cerevisiae for intracellular metabolite monitoring and genetic screening. ACS Synth. Biol. 2015, 4, 1308-1315. [CrossRef] [PubMed]

31. DeLoache, W.C.; Russ, Z.N.; Narcross, L.; Gonzales, A.M.; Martin, V.J.J.; Dueber, J.E. An enzyme-coupled biosensor enables (S)-reticuline production in yeast from glucose. Nat. Chem. Biol. 2015, 11, 465-471. [CrossRef] [PubMed]

32. Dietrich, J.A.; Shis, D.L.; Alikhani, A.; Keasling, J.D. Transcription Factor-Based Screens and Synthetic Selections for Microbial Small-Molecule Biosynthesis. ACS Synth. Biol. 2013, 2, 47-58. [CrossRef] [PubMed]

33. Schendzielorz, G.; Dippong, M.; Grünberger, A.; Kohlheyer, D.; Yoshida, A.; Binder, S.; Nishiyama, C.; Nishiyama, M.; Bott, M.; Eggeling, L. Taking Control over Control: Use of Product Sensing in Single Cells to Remove Flux Control at Key Enzymes in Biosynthesis Pathways. ACS Synth. Biol. 2014, 3, 21-29. [CrossRef] [PubMed]

34. Raman, S.; Rogers, J.K.; Taylor, N.D.; Church, G. Evolution-guided optimization of biosynthetic pathways. Proc. Natl. Acad. Sci. USA 2014, 111, 17803-17808. [CrossRef]

35. Chou, H.H.; Keasling, J. Programming adaptive control to evolve increased metabolite production. Nat. Commun. 2013, 4, 2595. [CrossRef]

36. Hossain, G.S.; Saini, M.; Miyake, R.; Ling, H.; Chang, M.W. Genetic Biosensor Design for Natural Product Biosynthesis in Microorganisms. Trends Biotechnol. 2020, 38, 797-810. [CrossRef]

37. Volke, D.C.; Turlin, J.; Mol, V.; Nikel, P.I. Physical decoupling of XylS/Pm regulatory elements and conditional proteolysis enable precise control of gene expression in Pseudomonas putida. Microb. Biotechnol. 2019, 13, 222-232. [CrossRef]

38. Rienzo, M.; Jackson, S.J.; Chao, L.K.; Leaf, T.; Schmidt, T.J.; Navidi, A.H.; Nadler, D.C.; Ohler, M.; Leavell, M.D. High-throughput screening for high-efficiency small-molecule biosynthesis. Metab. Eng. 2021, 63, 102-125. [CrossRef]

39. Zhang, F.; Carothers, J.; Keasling, J. Design of a dynamic sensor-regulator system for production of chemicals and fuels derived from fatty acids. Nat. Biotechnol. 2012, 30, 354-359. [CrossRef]

40. Doong, S.J.; Gupta, A.; Prather, K.L.J. Layered dynamic regulation for improving metabolic pathway productivity in Escherichia coli. Proc. Natl. Acad. Sci. USA 2018, 115, 2964-2969. [CrossRef]

41. Calero, P.; Volke, D.C.; Lowe, P.T.; Gotfredsen, C.H.; O’Hagan, D.; Nikel, P.I. A fluoride-responsive genetic circuit enables in vivo biofluorination in engineered Pseudomonas putida. Nat. Commun. 2020, 11, 1-11. [CrossRef] [PubMed]

42. Machado, L.F.M.; Currin, A.; Dixon, N. Directed evolution of the PcaV allosteric transcription factor to generate a biosensor for aromatic aldehydes. J. Biol. Eng. 2019, 13, 91. [CrossRef] [PubMed]

43. Fiorentino, G.; Ronca, R.; Bartolucci, S. A novel E. coli biosensor for detecting aromatic aldehydes based on a responsive inducible archaeal promoter fused to the green fluorescent protein. Appl. Microbiol. Biotechnol. 2009, 82, 67-77. [CrossRef] 
44. Frazão, C.R.; Maton, V.; François, J.M.; Walther, T. Development of a Metabolite Sensor for High-Throughput Detection of Aldehydes in Escherichia Coli. Front. Bioeng. Biotechnol. 2018, 6. [CrossRef]

45. Colepicolo, P.; Cho, K.W.; Poinar, G.O.; Hastings, J.W. Growth and luminescence of the bacterium Xenorhabdus luminescens from a human wound. Appl. Environ. Microbiol. 1989, 55, 2601-2606. [CrossRef]

46. Ressmann, A.; Schwendenwein, D.; Leonhartsbgerger, S.; Mihovilovic, M.D.; Bornscheuer, U.; Winkler, M.; Rudroff, F. SubstrateIndependent High-Throughput Assay for the Quantification of Aldehydes. Adv. Synth. Catal. 2019, 361, 2538-2543. [CrossRef]

47. Kitov, P.I.; Vinals, D.F.; Ng, S.; Tjhung, K.F.; Derda, R. Rapid, Hydrolytically Stable Modification of Aldehyde-Terminated Proteins and Phage Libraries. J. Am. Chem. Soc. 2014, 136, 8149-8152. [CrossRef] [PubMed]

48. Santala, S.M.; Efimova, E.; Karp, M.; Santala, V. Real-Time monitoring of intracellular wax ester metabolism. Microb. Cell Fact. 2011, 10, 75. [CrossRef]

49. Zhang, Y.; Werling, U.; Edelmann, W. SLiCE: A novel bacterial cell extract-based DNA cloning method. Nucleic Acids Res. 2012, 40, e55. [CrossRef]

50. Wiesinger, T.; Bayer, T.; Milker, S.; Mihovilovic, M.D.; Rudroff, F. Cell factory design and optimization for the stereoselective synthesis of polyhydroxylated compounds. ChemBioChem 2018, 19, 361-368. [CrossRef]

51. Heath, R.S.; Birmingham, W.R.; Thompson, M.P.; Taglieber, A.; Daviet, L.; Turner, N.J. An Engineered Alcohol Oxidase for the Oxidation of Primary Alcohols. ChemBioChem 2018, 20, 276-281. [CrossRef] [PubMed]

52. Finnigan, W.; Thomas, A.; Cromar, H.; Gough, B.; Snajdrova, R.; Adams, J.P.; Littlechild, J.A.; Harmer, N.J. Characterization of Carboxylic Acid Reductases as Enzymes in the Toolbox for Synthetic Chemistry. ChemCatChem 2017, 9, 1005-1017. [CrossRef] [PubMed]

53. Akhtar, M.K.; Turner, N.J.; Jones, P. Carboxylic acid reductase is a versatile enzyme for the conversion of fatty acids into fuels and chemical commodities. Proc. Natl. Acad. Sci. USA 2013, 110, 87-92. [CrossRef] [PubMed]

54. Horvat, M.; Winkler, M. In VivoReduction of Medium- to Long-Chain Fatty Acids by Carboxylic Acid Reductase (CAR) Enzymes: Limitations and Solutions. ChemCatChem 2020, 12, 5076-5090. [CrossRef]

55. Del Solar, G.; Giraldo, R.; Ruiz-Echevarría, M.J.; Espinosa, M.; Díaz-Orejas, R. Replication and control of circular bacterial plasmids. Microbiol. Mol. Biol. Rev. 1998, 62, 434-464. [CrossRef]

56. Van Beilen, J.B.; Eggink, G.; Enequist, H.; Bos, R.; Witholt, B. DNA sequence determination and functional characterization of the OCT plasmid-encoded alkJKL genes of Pseudomonas oleovorans. Mol. Microbiol. 1992, 6, 3121-3136. [CrossRef]

57. Juven, B.J.; Pierson, M.D. Antibacterial Effects of Hydrogen Peroxide and Methods for Its Detection and Quantitationt. J. Food Prot. 1996, 59, 1233-1241. [CrossRef]

58. Milker, S.; Gonçalves, L.; Fink, M.J.; Rudroff, F. Escherichia coli Fails to Efficiently Maintain the Activity of an Important Flavin Monooxygenase in Recombinant Overexpression. Front. Microbiol. 2017, 8, 2201. [CrossRef]

59. Mueller, N.J.; Stueckler, C.; Hauer, B.; Baudendistel, N.; Housden, H.; Bruce, N.C.; Faber, K. The Substrate Spectra of Pentaerythritol Tetranitrate Reductase, Morphinone Reductase, N-Ethylmaleimide Reductase and Estrogen-Binding Protein in the Asymmetric Bioreduction of Activated Alkenes. Adv. Synth. Catal. 2010, 352, 387-394. [CrossRef]

60. Peters, C.; Kölzsch, R.; Kadow, M.; Skalden, L.; Rudroff, F.; Mihovilovic, M.D.; Bornscheuer, U.T. Identification, characterization and application of three enoate reductases from Pseudomonas putida in in vitro enzyme cascade reactions. ChemCatChem 2014, 6, $1021-1027$. [CrossRef]

61. Richardson, K.N.; Black, W.B.; Li, H. Aldehyde production in crude lysate- and whole cell-nased biotransformation using a noncanonical redox cofactor system. ACS Catal. 2020, 10, 889-903. [CrossRef]

62. Williams, R.E.; Bruce, N.C. 'New uses for an old enzyme'-The old yellow enzyme family of flavoenzymes. Microbiology 2002, 148, 1607-1614. [CrossRef]

63. Liang, X.; Thorpe, C.; Schulz, H. 2,4-Dienoyl-CoA reductase from Escherichia coli is a novel iron-sulfur flavoprotein that functions in fatty acid $\beta$-oxidation. Arch. Biochem. Biophys. 2000, 380, 373-379. [CrossRef] [PubMed]

64. Lee, J. Perspectives on Bioluminescence Mechanisms. Photochem. Photobiol. 2016, 93, 389-404. [CrossRef]

65. Jimenez-Diaz, L.; Caballero, A.; Segura, A. Pathways for the Degradation of Fatty Acids in Bacteria. In Aerobic Utilization of Hydrocarbons, Oils and Lipids; Rojo, F., Ed.; Springer Internationl Publishing: Cham, Switzerland, 2017; pp. 1-23. [CrossRef]

66. Janßen, H.J.; Steinbüchel, A. Fatty acid synthesis in Escherichia coli and its applications towards the production of fatty acid based biofuels. Biotechnol. Biofuels 2014, 7, 7. [CrossRef] [PubMed]

67. Wiltschi, B.; Cernava, T.; Dennig, A.; Casas, M.G.; Geier, M.; Gruber, S.; Haberbauer, M.; Heidinger, P.; Acero, E.H.; Kratzer, R.; et al. Enzymes revolutionize the bioproduction of value-added compounds: From enzyme discovery to special applications. Biotechnol. Adv. 2020, 40, 107520. [CrossRef]

68. Li, C.; Zhang, R.; Wang, J.; Wilson, L.M.; Yan, Y. Protein Engineering for Improving and Diversifying Natural Product Biosynthesis. Trends Biotechnol. 2020, 38, 729-744. [CrossRef] [PubMed]

69. Fleiss, A.; Sarkisyan, K.S. A brief review of bioluminescent systems. Curr. Genet. 2019, 65, 877-882. [CrossRef]

70. Kim, J.-K.; Kang, C.-S.; Lee, J.-K.; Kim, Y.-R.; Han, H.-Y.; Yun, H.K. Evaluation of Repellency Effect of Two Natural Aroma Mosquito Repellent Compounds, Citronella and Citronellal. Entomol. Res. 2005, 35, 117-120. [CrossRef]

71. Nakahara, K.; Alzoreky, N.S.; Yoshihashi, T.; Nguyen, H.T.T.; Trakoontivakorn, G. Chemical Composition and Antifungal Activity of Essential Oil from Cymbopogon nardus (Citronella Grass). JARQ 2013, 37, 249-252. [CrossRef]

72. Piancatelli, G.; Leonelli, F. Oxidation of nerol to neral with iodobenzene diacetate and TEMPO. Org. Synth. 2006, 83, 1. [CrossRef] 
73. Müller, G.C.; Junnila, A.; Kravchenko, V.D.; Revay, E.E.; Butler, J.; Orlova, O.B.; Weiss, R.W.; Schlein, Y. Ability of essential oil candles to repel biting insects in high and low biting pressure environments. J. Am. Mosq. Control Assoc. 2008, 24, 154-160. [CrossRef]

74. Clark, B.; Powell, C.; Radford, T. The acid catalyzed cyclization of citral. Tetrahedron 1977, 33, 2187-2191. [CrossRef]

75. Parker, G.; Smith, L.; Baxendale, I. Development of the industrial synthesis of vitamin A. Tetrahedron 2016, 72, 1645-1652. [CrossRef]

76. Li, C.; Wen, A.; Shen, B.; Lu, J.; Huang, Y.; Chang, Y. FastCloning: A highly simplified, purification-free, sequence- and ligation-independent PCR cloning method. BMC Biotechnol. 2011, 11, 92. [CrossRef]

77. Julsing, M.K.; Schrewe, M.; Cornelissen, S.; Hermann, I.; Schmid, A.; Bühler, B. Outer Membrane Protein AlkL Boosts Biocatalytic Oxyfunctionalization of Hydrophobic Substrates in Escherichia coli. Appl. Environ. Microbiol. 2012, 78, 5724-5733. [CrossRef]

78. Studier, F.W. Protein production by auto-induction in high-density shaking cultures. Protein Expr. Purif. 2005, 41, 207-234. [CrossRef] 